\title{
A Hybrid Decision Support System for Managing Humanitarian Relief Chains
}

\author{
Navid Sahebjamnia ${ }^{\mathrm{a}, 1}$, S. Ali Torabi ${ }^{\mathrm{b}}$, S. Afshin Mansouri ${ }^{\mathrm{c}}$ \\ ${ }^{a}$ Department of Industrial Engineering, University of Science and Technology of Mazandaran, Behshahr, Iran \\ ${ }^{b}$ School of Industrial Engineering, College of Engineering, University of Tehran, Tehran, Iran \\ ${ }^{\mathrm{c}}$ Brunel Business School, Brunel University London, United Kingdom
}

\begin{abstract}
Decisions regarding location, allocation and distribution of relief items are among the main concerns of the Humanitarian Relief Chain (HRC) managers in response to no-notice large-scale disasters such as earthquakes. In this paper, a Hybrid Decision Support System (HDSS) consisting of a simulator, a rule-based inference engine, and a knowledge-based system (KBS) is developed to configure a three level HRC. Three main performance measures including the coverage, total cost, and response time are considered to make an explicit trade-off analysis between cost efficiency and responsiveness of the designed HRC. In the first step, the simulator calculates the performance measures of the different configurations of the HRC under generated number of disaster scenarios. Then, the rule-based inference engine attempts to build the best configuration of the HRC including facilities' locations, relief items' allocation and distribution plan of the scenario under investigation based on calculated performance measures. Finally, the best configuration for each scenario is stored in the KBS as the extracted knowledge from the above analyses. In this way, the HRC managers can retrieve the most appropriate HRC configuration in accordance with the realized post-disaster scenario in an effective and timely manner. The results of a real case study in Tehran demonstrate that the developed HDSS is an effective tool for fast configuration of HRCs using stochastic data.
\end{abstract}

Keywords: Decision support system; Humanitarian relief chain; Rule-based simulator; Knowledge-based system; Integrated relief prepositioning and distribution.

\section{Introduction}

The growing trend of natural and man-made disasters has led to considerable increase in the number of studies in the context of Humanitarian Relief Chain (HRC) management in recent years. Since quick response to the urgent needs of the affected people is critical for the effective management of HRCs, scholars have developed different decision models for managing HRCs. Fritz Institute [1] reported that lack of a system for monitoring and managing the relief aids in 2004 Southeast Asia tsunami led to large-scale shortages of relief items and medical personnel.

${ }^{1}$ Corresponding author: Tel: +989111282680

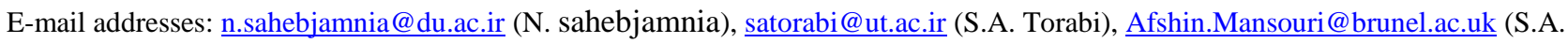
Mansouri). 


\section{Nomenclature}

\begin{tabular}{|c|c|c|c|}
\hline \multicolumn{2}{|l|}{ Indices } & \multirow{2}{*}{$\begin{array}{l}L T_{i} \\
L T_{j}^{z}\end{array}$} & \multirow{2}{*}{$\begin{array}{l}\text { Lead time of CT } i \text { for relief item } n \\
\text { Lead time of LT type } j \text { in zone } z \text { for relief item } n\end{array}$} \\
\hline$j$ & Index of LT's type $(j=1, \ldots, J)$ & & \\
\hline$i$ & Index of CTs $(i=1, \ldots I)$ & $C_{i}^{C T}$ & Setup cost of CT $i$ \\
\hline$z$ & Index of zones $(z=1, \ldots Z)$ & $C_{j z}^{L T}$ & Setup cost of LT type $j$ in zone $z$ \\
\hline$n$ & Index of relief items $(n=1, \ldots N)$ & {$\left[\Upsilon^{-}, \Upsilon^{+}\right.$} & $\begin{array}{l}\text { Satisfaction range of LTs' total setup cost in the } \\
\text { designed HRC }\end{array}$ \\
\hline$u$ & Index of injury rate $(u=l, m, h)$ & {$\left[\Delta^{-}, \Delta^{+}\right.$} & $\begin{array}{l}\text { Satisfaction range of CTs' total setup cost in the } \\
\text { designed HRC }\end{array}$ \\
\hline$q$ & Index of HOs, $(q=1, \ldots, Q)$ & {$\left[\Lambda^{-}, \Lambda^{+}\right.$} & $\begin{array}{l}\text { Satisfaction range of total transportation cost in } \\
\text { the designed HRC }\end{array}$ \\
\hline$e$ & Index of transportation modes, $(e=1, \ldots, E)$ & {$\left[\Gamma^{-}, \Gamma^{+}\right.$} & $\begin{array}{l}\text { Satisfaction range of total shortage of relief } \\
\text { items in the designed HRC }\end{array}$ \\
\hline \multicolumn{2}{|c|}{ Parameters (primary data) } & {$\left[\Psi^{-}, \Psi^{+}\right.$} & $\begin{array}{l}\text { Satisfaction range of total excess of relief items } \\
\text { in the designed HRC }\end{array}$ \\
\hline$\lambda_{n}^{l}, \lambda_{n}^{m}, \lambda_{n}^{h}$ & $\begin{array}{l}\text { Amount of relief item } n \text { needed by affected people } \\
\text { with low } \lambda_{n}^{l} \text {, medium } \lambda_{n}^{m} \text { and high injury level } \lambda_{n}^{h}\end{array}$ & {$\left[\mathrm{I}^{-}, \mathrm{I}^{+}\right]$} & $\begin{array}{l}\text { Satisfaction range of LTs' total lead time in the } \\
\text { designed HRC }\end{array}$ \\
\hline$P_{z}$ & The number of wounded people in zone $z$ & {$\left[\Phi^{-}, \Phi^{+}\right.$} & $\begin{array}{l}\text { Satisfaction range of CTs' total lead time in the } \\
\text { designed HRC }\end{array}$ \\
\hline$C_{n}^{u}$ & $\begin{array}{l}\text { Amount of relief items } n \text { needed by wounded people } \\
\text { with injury rate } u\end{array}$ & \multicolumn{2}{|c|}{ Parameters (secondary data) } \\
\hline$\eta_{z}^{u}$ & $\begin{array}{l}\text { Percentage of wounded people with injury rate } u \text { in } \\
\text { zone } z\end{array}$ & $d_{n}^{z}$ & Demand of relief item $n$ in zone $z$ \\
\hline$\xi_{j n}^{L T}$ & Output rate of LT type $j$ for relief item $n$ & $\mathrm{RS}$ & Total resource shortage \\
\hline$\psi_{j n}^{L T}$ & Input rate of LT type $j$ for relief item $n$ & $\mathrm{RE}$ & Total resource excess \\
\hline$S_{j n}^{L T}$ & Capacity of LT type $j$ for relief item $n$ & $\mathrm{TC}$ & Total cost of the relief chain \\
\hline$\xi_{\text {in }}^{C T}$ & Output rate of $i^{\text {th }} \mathrm{CT} i$ for relief item $n$ & $C^{C o}$ & Total transportation cost \\
\hline$\psi_{i n}^{C T}$ & Input rate of CT $i$ for relief item $n$ & $C^{C T}$ & Total setup cost of CTs \\
\hline$S_{i n}^{C T}$ & Capacity of CT $i$ for relief item $n$ & $C^{L T}$ & Total setup cost of LTs \\
\hline$\xi_{q n}^{H O}$ & Output rate of $\mathrm{HO} q$ for relief item $n$ & $L T^{L T}$ & Total lead time of LTs \\
\hline$\hat{L}_{j}^{z}$ & Number of available LT type $j$ in zone $z$ & $L T^{C T}$ & Total lead time of CTs \\
\hline$L$ & Set of available CTs & \multicolumn{2}{|c|}{ Decision variables } \\
\hline$d_{i j z}$ & Distance between CT $i$ and LT $j$ in zone $z$ & $L_{j}^{z}$ & $\begin{array}{l}\text { Number of required LTs of type } j \text { which are } \\
\text { setup in zone } z\end{array}$ \\
\hline$d_{q i}$ & Distance between $\mathrm{HO} q$ and CT $i$ & $\theta$ & Number of required CTs \\
\hline$R_{j}$ & $\begin{array}{l}\text { The set of relief items that can be delivered by LT type } \\
j\end{array}$ & $\theta_{i}$ & 1: if CT $i$ is setup; 0 : otherwise \\
\hline$E T_{i q}^{e}$ & $\begin{array}{l}\text { Transportation time between } \mathrm{HO} q \text { and CT } i \text { by } \\
\text { transportation mode } e\end{array}$ & $F_{i j n}^{z}$ & $\begin{array}{l}\text { Distributed amount of relief item type } n \text { to } \mathrm{LT} j \\
\text { in zone } z \text { from CT } i\end{array}$ \\
\hline$E T_{i j}^{e}$ & $\begin{array}{l}\text { Transport time between CT } i \text { and } \mathrm{LT} j \text { by } \\
\text { transportation mode } e\end{array}$ & $F_{q n i}$ & $\begin{array}{l}\text { Distributed amount of relief item type } n \text { to } \mathrm{CT} i \\
\text { from } \mathrm{HO} q\end{array}$ \\
\hline$\vec{E}_{e}$ & Attribute vector of transportation mode $e$ & $v_{i e}^{q n}$ & $\begin{array}{l}\text { 1: if transportation mode } e \text { is selected for } \\
\text { transferring relief item } n \text { from } \mathrm{HO} q \text { to CT } i ; 0 \text { : } \\
\text { otherwise }\end{array}$ \\
\hline$E_{e}^{v}$ & Speed of transportation mode $e$ & $v_{\text {ine }}^{z j}$ & $\begin{array}{l}\text { 1: if transportation mode } e \text { is selected for } \\
\text { transferring relief item } n \text { from CT } i \text { to LT } j \text { of } \\
\text { zone } z ; 0 \text { : otherwise }\end{array}$ \\
\hline$E_{e}^{c a}$ & Capacity of transportation mode $e$ & $U_{e}$ & The number of utilized transportation mode $e$ \\
\hline$E_{e}^{c o}$ & Unit cost of transportation mode $e$ & & \\
\hline
\end{tabular}


The report discussed the main problems of the management of HRCs that motivated recent research studies to focus on facility location [2], relief items' allocation [3], and relief distribution/transportation issues [4]. These problems in the context of humanitarian supply chains are different from their counterparts in commercial supply chains in which, timeliness and effectiveness of relief operations are more important factors than cost [5]. However, there are few studies that account for these unique features of HRCs and incorporating multiple factors for trade-off analysis of cost efficiency and responsiveness measures [6]. In this regard, practitioners need more applicable methods that can help them manage HRCs more effectively by considering their main characteristics $[7,8]$.

Among different decision making methods, Decision Support Systems (DSS) have great potential to contribute to HRC operations management given their successful implementations in a wide range of applications (e.g. [911]). Gutjahr and Nolz [12] emphasized that HRCs' actors need suitable DSS to manage HRCs. In addition, some research studies [7, 8, 12-14] explored different features of the HRCs management. The features that necessitate developing DSS in the HRC context are including. i) Need for rapid response in the face of large amount of data; ii) The limitation of the HRCs' resources such as relief items and transportation equipment; iii) Deep uncertainty in data due to unpredictable situation in post disaster phase; iv) The unpredictable nature of disasters such as their timing, severity, and impact.

Despite the urgent need for developing suitable DSS for effective management of HRCs, our literature review reveals a development gap for DSS with the aforementioned characteristics. Indeed, lack of some key features in existing DSS for responding to large-scale no-notice disasters such as earthquake and flood is evident. We argue that a hybrid DSS consisting of a knowledge base and a rule-based simulator in a unified framework can meet the above requirements. Successful implementation of such hybrid DSS in other contexts (see [5, 15-17]) has been the main motivation for the current research in the context of HRC. In this paper, a hybrid decision support system (HDSS) is developed to support HRCs' managers when facing with large scale and no-notice disasters such as an earthquake. The developed HDSS can increase the effectiveness and efficiency of the decisions made by HRC's managers by considering three relevant factors including the relief items' coverage, total cost, and response time. The HDSS determines the number of required central terminals (CTs) and local terminals (LTs), as well as the allocation pattern and distribution of relief items based on the different probable scenarios in post disaster phase. The proposed HDSS includes a rule-based simulator to explore a set of effective and efficient decisions by applying a rule-based mechanism and simulating the post-disaster conditions in the pre-disaster phase for each set of possible scenarios and decision variables. The results of the rule-based simulator are then used to develop/update a knowledge-based system. Accordingly, the KBS can be employed for managing relief operations in unpredictable and complicated post-disaster situations in real time. The main contributions of this paper can be highlighted as follows: 
- designing a HDSS to timely manage the HRC-related activities;

- incorporating a simulation model to assess the post-disaster situation with two categories of rules;

- utilizing outcomes of the rule-based simulator to form/update the knowledge base of HDSS;

- demonstrating the tangible benefits of the proposed HDSS using a real case study.

\section{Literature review}

Based on the characteristics of the proposed HDSS for HRCs, the most relevant literature is reviewed in two different but related streams: humanitarian relief chain design and decision support systems for HRCs.

\subsection{Humanitarian relief chain design}

The number of HRC research output has increased significantly since 2010 in light of the growing trend of natural and man-made disasters across the world. There are different features that complicates management of the HRCs. Wolshon et al. [18] defined short-notice disasters with lead-time between 24 and 72 hours, which allow decision makers to form an effective HRC. In contrast, a no-notice disaster like an earthquake occurs without any warning. Effective and real-time emergency response to a no-notice disaster is an extremely challenging endeavor, which needs a coordinated and integrated decision process [19]. Unfortunately a majority of proposed mathematical formulations in the literature are computationally intractable and HRC practitioners cannot use them effectively [20]. Consequently, there is a need for decision models that can provide real-time response to unpredictable and changeable situations after no-notice disasters to fulfill the needs of HRC managers. From a different perspective and according to the disaster life cycle, two main phases consisting of pre- and post-disaster phases were distinguished by Tufekci and Wallace [21]. Caunhye et al. [22] mentioned that many operations of HRCs are implemented across both phases such as facility location, inventory planning and capacity planning and this feature should be considered carefully when designing a HRC. Nevertheless, the review of Galindo and Batta [23] showed that the majority of scholars separate these phases although this may lead to suboptimal solutions for the whole $\operatorname{HRC}[19,24]$. Consequently, there is a real need for developing an effective decision making framework for preparing and assessing suitable response plans according to the realized disaster scenario at post-disaster phase.

These problems in the context of humanitarian supply chains are different from their counterparts in commercial supply chains in which, timeliness and effectiveness of relief operations are more important factors than cost. Indeed, humanitarian supply chains' managers should analyze the trade-off between efficiency and effectiveness factors. Recently, Gutjahr and Nolz [12] reviewed the literature on quantitative HRC models that use multicriteria optimization methods. They explored eight measures, which are frequently used for managing and evaluating HRCs such as cost, response time, travel distance, and coverage. HRC coordinators need to 
understand and interpret the trade-offs between different measures quickly in changing and dynamic situation of real world problems [12]. Therefore, developing multi-objective optimization models for HRCs raises enormous challenges [25]. Among various approaches, DSS can accommodate the changing and unpredictable nature of such multi-objective problems [12]. Accordingly, in the existence of multiple measures for managing HRCs and given the necessity of making trade-off analysis between them, DSS could be an applicable modeling framework. As an example, Rakes [26] designed a DSS for making specific recommendations to families with respect to their interim housing alternatives after disasters by considering different measures. Due to the special nature of no-notice disasters, decision makers cannot determine their timing, severity, and resulting impacts easily. Therefore, the HRC managers have to coordinate their operations in pre- and post-disasters phases with incomplete and inexact information. Liberatore et al. [27] categorized the methods and approaches that scholars have used to tackle uncertainties in HRCs into four main categories consisting of simulation modeling, stochastic programming, robust optimization, and fuzzy programming. Their review showed that the majority of the contributions in the context of HRC design used stochastic or/and possibilistic programming techniques. The application of these studies in practice is limited due to their computational complexity. Indeed, HRC practitioners need more practical decision models enabling them to manage HRCs effectively while helping HRC actors to learn from previous disaster responses [27]. By summarizing the literature, the main issues that should be considered when developing HRC decision models consist of i) capability of the model to update the response plans in real time; ii) applicability of the model by HRC practitioners in real world situations; iii) ability of the model to consider the interrelationships between the pre- and post-disaster decisions in an integrated way; iv) competency of the model to manage and coordinate the HRC in dynamic situation of postdisaster phase; v) capability of the model for trade-off analysis between multiple performance measures.

\subsection{Decision support systems for HRCs}

Decision support systems are used in a variety of commercial supply chain problems such as inventory management [28], transportation problem [29, 30], supplier selection [31], information sharing [32], procurement management [33], and order allocation [34]. Nevertheless, few studies can surprisingly be reported that develop DSS for coordinating and managing HRCs. Van de Walle and Turoff [35] categorized DSS for emergency situations according to the different phases of disaster. They developed and implemented a DSS in response to large-scale disasters such as Indian Ocean tsunami, and hurricane Katrina. Geldermann et al. [36] designed a DSS to provide response plans from early response to recovery phases in the event of a nuclear accident in Europe. Their work shows the role of DSS in ensuring the transparency of decision processes in the emergency situatuions.

Ortuño et al. [37] presented a DSS for HRC operations and validated it using a real world problem regarding food crisis in Niger. They compared their results with the current practice. Shan et al. [38] emphasized that DSS 
are capable to assist HRC managers for evaluating emergency response plans in the pre- and postdisaster phases. Xanthopoulos and Koulouriotis [39] proposed a bi-level multi-agent system for relief distribution operations in the post-disaster phase. Their framework has the ability to re-route the distribution plans upon incoming information in the post-disaster phase. Kumar and Havey [40] proposed a DSS by identifying and quantifying different risks at different phases of HRC. Florez et al. [2] developed a DSS to manage the response to a disaster in spite of failures or shortages of infrastructure and resources. They utilized artificial intelligence to solve facility location and pre-positioning problems in HRCs by defining different scenarios.

Our literature review demonstrates the usefulness and applicability of DSS for managing HRCs in several real cases. Indeed, HRC managers can rely on DSS more than other techniques such as mathematical models due to complexity, uncertainty and urgency of emergency decision making in HRCs [41, 42]. The criticality of relief operations in reducing the suffering of affected people in the first few hours after a disaster strikes [43], gives rise to the importance of developing integrated DSS that can help emergency operations managers. Based on above discussion, there is a huge need for the development of integrated decision support systems to support quick decision making in the dynamic and uncertain environment of the post-disaster phase. Most of the earlier research works have focused on either resource allocation or distribution planning. There is a gap in tackling these problems jointly through an effective while real time decision-making framework. This paper aims to address this gap by developing a hybrid decision support system for efficient and effective management of HRCs.

\section{The proposed HDSS model}

In this paper, we address a three-layer HRC, which includes multiple HOs, CTs and LTs. HOs from all around the world send relief items to CTs located near the affected area. At the last layer, the relief items are distributed from CTs to LTs located at different zones within the affected areas. Facility location and routing problems (including the relief items' allocation and transportation decisions) are addressed as the focuses of the HRC under consideration. While the facility location decisions are addressed at the pre-disaster phase, the routing decisions are made at the post-disaster phase. Therefore, the developed HRC model is bi-phase that involves both pre- and post-disaster decisions jointly. In this manner, HRCs' managers can distribute required relief items to the affected areas rapidly to minimize the human suffering and death [13]. Consequently, the developed HDSS supports HRCs' managers by providing real time and effective decisions in the following subjects:

- the number and locations of required CTs;

- the number of LTs of different types (such as shelters) in each affected zone;

- the amount of distributed relief items and employed transportation modes from HOs to CTs;

- route selection for sending relief items from HOs to CTs and from CTs to LTs. 


\subsection{Problem description}

We have adapted the idea of Gatignon et al. [44] in splitting the affected area into the different zones based on their infrastructure, population, and vulnerability. A three-layer HRC including multiple international and local HOs, CTs and LTs. HOs are either governmental or non-governmental humanitarian organizations who concern with human welfare and social reform such as the International Federation of Red Cross (IFRC). HOs dispatch relief items to CTs at the rates given by $\xi_{q n}^{H O}$ (i.e. the amount of supplied relief item $n$ by HO $q$ per unit of time) after the disaster strikes from all around the world. A CT is a warehouse or depot that receives different relief items from HOs at rates specified by $\psi_{i n}^{C T}$ (i.e. the amount of relief item $n$ sent to CT $i$ per unit of time) and dispatches them among affected people through LTs at rates given by $\xi_{\text {in }}^{C T}$ (i.e. the amount of relief item $n$ distributed from CT $i$ per unit of time). Train stations, airports, seaports and local depots are some examples, which could be used as CTs. Similar to CTs, LTs receive and distribute the relief items to the affected people at the rates given by $\psi_{j n}^{L T}$ and $\xi_{j n}^{L T}$ (i.e. the amounts of relief item $n$ sent to/distributed from LT $j$ per unit of time) respectively. According to the needs of each zone, diverse types of LTs might be setup for different relief items (such as shelters and medical) in each zone. While CTs are shared by all zones, LTs are allocated to individual zones (allocation variables are denoted by $l_{j}^{z}$ indicating the allocation of zone $z$ to LT $j$ ).

When a disaster happens, HOs and local suppliers start to transfer the relief items to the CTs from which, they are distributed to different zones. Since, any delay in delivering relief items may increase the number of casualties, capacity of the CTs and LTs should be sufficient to accommodate the arriving relief items. In fact, the performance of the CTs and LTs are critical which affect the quality and timeliness of the designed HRC. CTs are characterized by their capacity, input and output rates as three parameters $\left(S_{i n}^{C T}, \psi_{i n}^{C T}, \xi_{i n}^{C T}\right)$. Similarly, each type of LTs has a definite capacity, input and output rate as three parameters $\left(\psi_{j n}^{L T}, \xi_{j n}^{L T}, S_{j n}^{L T}\right)$. When the severity and resulting impact of a disaster increase, more LTs and CTs should be setup. In this manner, the speed of relief operation is increased and the impact of disaster would be decreased. At the post-disaster phase, let us assume that $P_{z}$ affected people need emergency aids in zone $z$. Each of them needs a different combination of relief items as represented by matrix $\lambda$ :

$$
\lambda=\left[\begin{array}{c}
\lambda_{n}^{l} \\
\lambda_{n}^{m} \\
\lambda_{n}^{h}
\end{array}\right]=\left[\begin{array}{cccc}
\lambda_{1}^{l} & \lambda_{2}^{l} & \ldots & \lambda_{N}^{l} \\
\lambda_{1}^{m} & \lambda_{2}^{m} & \ldots & \lambda_{N}^{m} \\
\lambda_{1}^{h} & \lambda_{2}^{h} & \ldots & \lambda_{N}^{h}
\end{array}\right]
$$


where $\lambda_{n}^{l}, \lambda_{n}^{m}, \lambda_{n}^{h}$ denote the amount of relief item type $n$ needed by each affected people with low, medium and high injury level, respectively. The HRC managers can estimate the amount of relief items based on different units (e.g. weight, number of packages and volume) or normalized values in terms of cost. It should be noted that according to the type and impacts of the disaster, people in affected area would have different levels of injuries. Therefore, injury level vector $\eta_{z}=\left(\eta_{z}^{l}, \eta_{z}^{m}, \eta_{z}^{h}\right)$ is defined to represent the percentage of the affected people with given injury level in each zone. This vector is estimated based on the geographical specification and population density of the zone $z$. In this way, the total demand for the relief item $n$ in zone $z$ is obtained from equation (2).

$d_{n}^{z}=P_{z} \cdot \sum_{u=l, m, h} \eta_{z}^{u} \cdot \lambda_{n}^{u} \quad \forall z, n$

Different transportation modes are available such as truck, helicopter, train and airplane. Each mode is

characterized by speed, capacity, and cost, which are denoted by $\vec{E}_{e}=\left(E_{e}^{v}, E_{e}^{c a}, E_{e}^{c o}\right)$. The relief items can be transferred from the HOs to the CTs and then from the CTs to the LTs by different transportation modes. It should be noted that some of transportation modes cannot be used between some terminals because of geographic/resource limitations or the distances between them. The transportation times between each pair of $\mathrm{HO}$ and $\mathrm{CT}$ and between each pair of CT and LT for each feasible transportation mode are denoted by $E T_{i q}^{e}$ and $E T_{i j}^{e}$, respectively.

\subsection{HRC performance measures}

The main objective of HRCs is to provide the required relief items to affected people in an effective, efficient and timely manner. Neely et al. [45] defined effectiveness as the extent to which consumer requirements are fulfilled and efficiency as a measure of how economically the resources are used at a given level of effectiveness. Although different criteria and performance measures have been proposed for managing commercial supply chains, limited attempt has been made in the context of HRCs [12]. Beamon and Balcik [46] presented a comparative study of performance measures in the HRCs with commercial supply chains. They emphasized that current performance measures for commercial supply chains can be adapted for HRCs. By reviewing the existing performance measures proposed in the literature (e.g. [47-50]) and considering characteristics of our concerned HRC, total shortage and excess amount of relief items are used to measure the effectiveness of the proposed HRC. Moreover, total cost and total delay assess the efficiency and timeliness of the proposed model.

\subsubsection{Assumptions}


The following assumptions have been made to develop appropriate performance measures for designing the HRC within the proposed HDSS:

- The demand in each zone can be estimated based on predictable factors such as injury rate, relief item combination matrix and disaster's specifications (such as gravity of earthquake).

- Alternative transportation modes (such as air carrier, trucks and railroad) are available.

- Each LT can support one or more types of relief items and services.

- The capacity of established CTs and LTs is sufficient to accommodate the arriving relief items.

- Multiple routes are available between HOs, CTs and LTs.

- HOs dispatch their relief items by air transportation mode.

- CTs are central storage locations that receive and store relief items (sent by HOs and/or supplied by the local suppliers) at pre- and early post-disaster, and distribute them among the LTs when a disaster strikes. Furthermore, LTs are some local facilities (like schools) inside the affected zones from which, the relief items are distributed to the affected people.

- Input/output rates of CTs and LTs denote the amount of relief items that could be received/transferred per unit time (e.g. an hour) during the relief operations.

- CTs and LTs have identical lead-time including loading, unloading, and waiting time for distributing relief items.

- A satisfaction range is determined for each performance measure by decision makers, which shows the allowed amounts of that measure in a relief distribution plan.

\subsubsection{Formulation}

Four performance measures have been formulated for the concerned HRC as follows:

\section{- Coverage (Relief items shortage and excess)}

For unforeseen, no-notice disasters, demand of relief items are uncertain in terms of timing, location, type, and size. The required set of relief items may differ greatly due to different features such as the type and severity of the disaster, demographics, as well as social and economic conditions of the affected area. Coverage measure is the degree to which relief items are provided to the affected people. In this respect, two types of relief items' performance metrics are defined as follows:

(1) Total shortage of relief items (RS) which is calculated by equation (3).

$R S=\left[\sum_{z=1}^{Z} \sum_{n=1}^{N}\left(d_{n}^{z}-\sum_{i=1}^{I} \sum_{j=1}^{J} F_{i j n}^{z}\right)\right] / \sum_{z=1}^{Z} \sum_{n=1}^{N} d_{n}^{z}$, if $d_{n}^{z}>\sum_{i=1}^{I} \sum_{j=1}^{J} F_{i j n}^{z}$; otherwise, $R S=0$. 
(2) Total excess of relief items (RE) which is estimated by equation (4).

$R E=\left[\sum_{z=1}^{Z} \sum_{n=1}^{N}\left(\sum_{i=1}^{I} \sum_{j=1}^{J} F_{i j n}^{z}-d_{n}^{z}\right)\right] / \sum_{z=1}^{Z} \sum_{n=1}^{N} d_{n}^{z}$, if $\sum_{i=1}^{I} \sum_{j=1}^{J} F_{i j n}^{z}>d_{n}^{z} ;$ otherwise, $R E=0$

\section{- $\quad$ Total cost}

The total cost of whole HRC consists of distribution costs and setup cost of facilities. HRCs frequently need to transport huge amounts of relief items in a short time. Nevertheless, the uncertain demand in the HRC makes the transportation planning more complicated and costly compared to the commercial supply chains. Additionally, the diversity of storage facilities with specific attributes, enforce the use of various transportation modes. Henceforth, the total cost of the whole relief chain $(T C)$ is estimated based on the total transportation $\operatorname{cost}\left(C^{C 0}\right)$ and setup cost for LTs $\left(C^{L T}\right)$ and CTs $\left(C^{C T}\right)$, as follows:

$T C=\sum_{z} \sum_{j} L_{j}^{z} \cdot C_{j z}^{L T}+\sum_{i=1}^{I} \theta_{i} \cdot C_{i}^{C T}+\sum_{e} U_{e} E_{e}^{C o}$

\section{- Response time}

In the context of HRCs, response time is one of the most critical performance measures. Many factors can affect the response time in a HRC, such as the number of HRC's entities (i.e. HO, CT, LT, and transportation equipment), the demand of relief items; remaining infrastructures of the affected area. To reduce the response time, we aim to decrease the total lead-time $(L T)$ as the total waiting time of relief items in the queue, which is calculated by equation (6). $L T_{j n}^{z}$ and $L T_{i n}$ include the loading, unloading and waiting times (in hours) of relief items in LTs and CTs, respectively. Lead times are measured by the time interval between the entrance and leaving of relief items in CTs and LTs during the simulation of post-disaster scenarios. LT can be decreased by setting up more CTs and LTs in the HRC.

$L T=L T^{L T}+L T^{C T}=\sum_{n=1}^{N} \sum_{z=1}^{Z} \sum_{i=1}^{I} \sum_{j=1}^{J} F_{i j n}^{z} \cdot L T_{j n}^{z}+\sum_{n=1}^{N} \sum_{q=1}^{Q} \sum_{i=1}^{I} F_{q n i} \cdot \theta_{i} \cdot L T_{i n}$

\section{HDSS framework}

In this section, the conceptual model of the proposed HDSS along with its elements is discussed. An interactive model combining a rule-based simulator with a knowledge-based system is developed to improve the performance of the HRCs. The structure of the proposed HDSS is shown in Figure 1. This figure illustrates how the rule-based simulator module interacts with the KBS. The initial situation of the concerned area such as geographical conditions and population information are stored as the input data. The simulation model estimates the performance measures' values for the configured HRC under possible scenarios in the affected area. Each 
disaster scenario involves the disaster type, its likelihood and impacts. If the satisfaction range of each performance measure (as defined by the decision makers) is not achieved, the HDSS recommends a new configuration for the HRC's network. This iterative process continues until satisfactory levels for all performance measures (equations 3-6) are achieved and an effective configuration of the HRC is reached. Then, the obtained configuration under each scenario is stored as the new knowledge in the knowledge base. In this way, the knowledge base is gradually updated. Indeed, HRCs' managers can retrieve the most efficient and effective configuration of the HRC network in accordance with the realized post-disaster situation quickly. In other words, in the post-disaster phase, HRC managers could select an effective HRC configuration based on the stored knowledge in the KB (i.e. the previously simulated/experienced configurations). Utilizing the rule-based simulator in the structure of proposed HDSS helps the HRCs' decision makers to evaluate various configurations of the HRC (i.e. the training capability feature) based on the different scenarios examined in the past (i.e. the particularly feature) in a timely manner. Moreover, the proposed HDSS increases the realism in experimental situations by simulating the real situations of any experiment. Finally, the interaction between the rule-based simulator and the knowledge-based system in the proposed HDSS helps the HRCs' managers to evaluate their decisions in the post-disaster phase and update their decisions by changing the satisfaction ranges of performance measures (i.e. the self-assessment feature).

The proposed HDSS consists of three sub-systems including the user interface, the knowledge based system, and the rule-based simulator that cover the HRC management lifecycle from the preparedness phase (in the predisaster phase) to the response phase (in the post-disaster phase). To increase the applicability of the proposed HDSS for HRC management, a common user interface is necessary. Ghandforoush and Sen [51] introduced the user interface as a critical element of the DSS that may affect the results. The fundamental characteristics of the user interface can be found in [52]. The structure of the user interface for disaster management should be simple such that users with minimum knowledge could interact with it conveniently. The user interface of the proposed HDSS has three main roles including: a) gathering information; b) reporting results; and c) setting decisionmaking parameters. The knowledge-based system is an interlayer section between the rule-base simulator and the user interface. Due to the nature of relief operations, knowledge based system should able to retrieve information precisely and quickly according to dynamic situation of the zones.

\subsection{The rule-based simulator}

The proposed rule-based simulator that is used in the preparedness phase prior to a disaster; is constructed in the four steps as follow:

\subsubsection{Step1: Data base formation}


All information about the concerned area such as geographical data, population, infrastructure, available terminals and shelters, safe and vulnerable places are gathered and stored in a database. The locations of the required CTs are identified based on the CTs' specifications such as setup cost, capacity, accessibility, input and output rates, capability and safety parameters. For example, train stations, airports and docks are the places that could be identified as CT. LTs are categorized into different types according to their specifications. For example, a hospital can be chosen for medical services and a school might be used as shelter.

\subsubsection{Step2: Disaster simulator}

Management of HRCs is very complex due to deep uncertainties about the specifications of no-notice disasters such as their timing, location, type, and size. Classical modeling approaches such as mathematical programming suffer from several limitations for dealing with the different complexities of HRCs. These include the need for rapid response and huge amount of decision variables, resource limitation, unpredictable situation and the unique nature of each disaster. The proposed simulation-based DSS makes it possible to re-evaluate the disruption risks, and re-generate and analyze decisions iteratively. Many researchers use simulation technique to formulate complex problems [53,54]. Arnott and Pervan [55] introduced the simulation technique as a valuable tool for experimental research in DSS. Fang and Marle [16] presented an integrated DSS based on simulation for modeling and management of project risks and risk interactions. Orta et. al [54] reviewed the simulation approaches that are used to support DSS in the context of the information technology service management. They found out that the simulation methods have important role in the DSSs' framework. Fanti et. al [56] develop a DSS to take tactical and operational decisions in logistics networks. They used simulation and optimization modules as the core of the DSS. Furthermore, their research demonstrates the capability of the simulation for dealing with complex problems under random uncertainty. We use the Discrete Event Simulation (DES) as the core of the HDSS to analyze and calculate the performance measures of any configured HRC network. In this way, DES is used to model different configurations of the HRC network. To this end, different post-disaster scenarios are first generated. Then, the performance measures of the configured HRC network are calculated under each scenario. Then, each HRC network configuration is created according to the calculated values for the decision variables (such as number of required LTs and CTs, distribution amounts of relief items, and transportation modes) iteratively. The details of the DES are provided in Appendix I. 


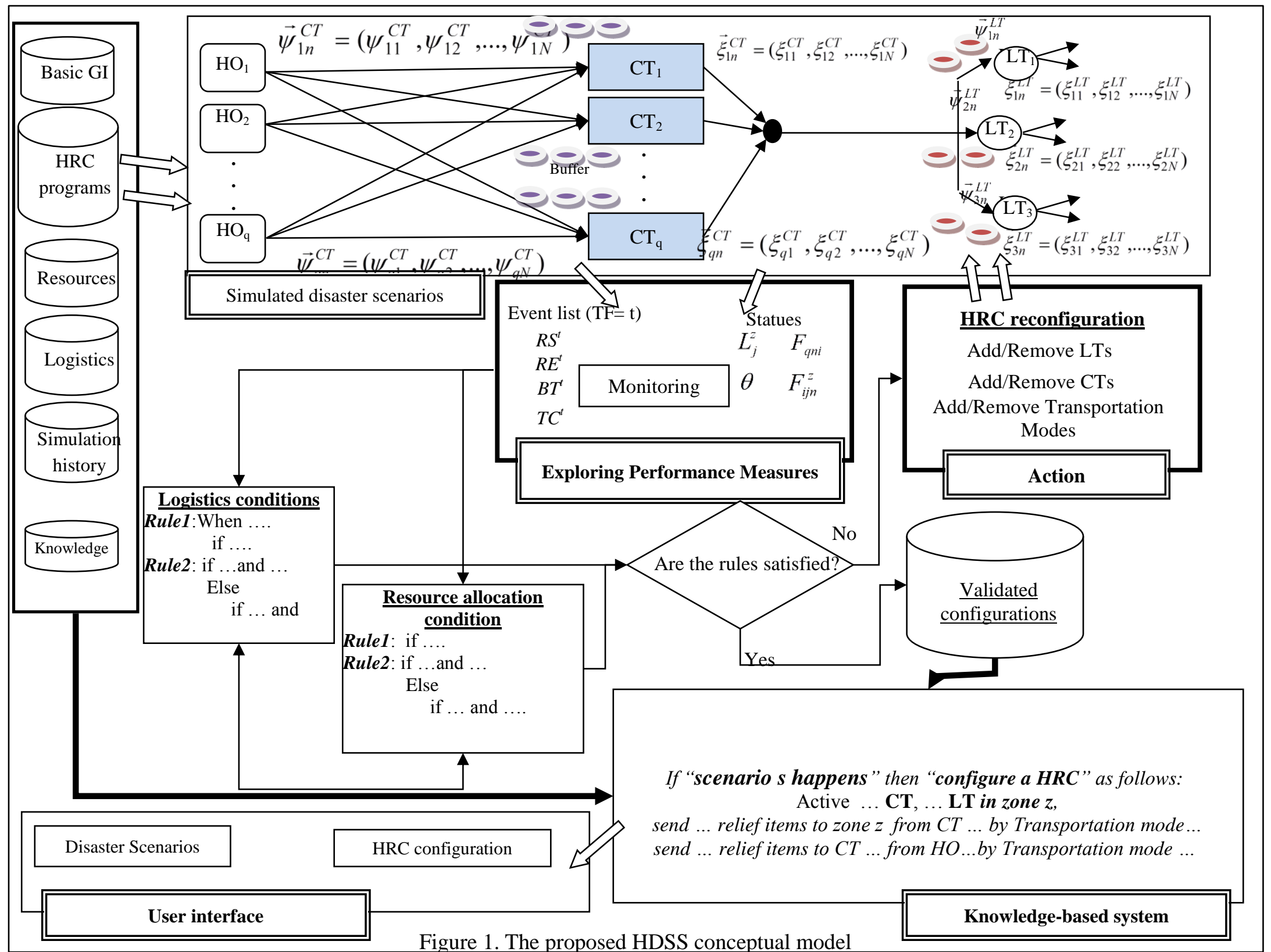


The proposed simulation-based DSS makes it possible to re-evaluate the disruption risks, and regenerate and analyze decisions iteratively. Many researchers use simulation technique to formulate complex problems $[53,54]$. Arnott and Pervan [55] introduced the simulation technique as a valuable tool for experimental research in DSS. Fang and Marle [16] presented an integrated DSS based on simulation for modeling and management of project risks and risk interactions. Orta et. al [54] reviewed the simulation approaches that are used to support DSS in the context of the information technology service management. They found out that the simulation methods have important role in the DSSs' framework. Fanti et. al [56] develop a DSS to take tactical and operational decisions in logistics networks. They used simulation and optimization modules as the core of the DSS. Furthermore, their research demonstrates the capability of the simulation for dealing with complex problems under random uncertainty.

In this research, we use the Discrete Event Simulation (DES) as the core of the HDSS to analyze and calculate the performance measures of any configured HRC network. In this way, DES is used to model different configurations of the HRC network. To this end, different post-disaster scenarios are first generated. Then, the performance measures of the configured HRC network are calculated under each scenario. Then, each HRC network configuration is created according to the calculated values for the decision variables (such as number of required LTs and CTs, distribution amounts of relief items, and transportation modes) iteratively. The details of the DES are provided in Appendix I.

\subsubsection{Step3: Rule-based inference engine}

The proposed adaptive controller consists of a simulator that exchanges data with a rule-based inference engine in the real-time manner. The simulator calculates the amount of performance measures and feeds them to the rule-based inference engine for each generated scenario. Then, the inference engine checks the conditions and recommends the possible improvements (if the satisfaction range are not achieved). The improved HRC network is rerun to re-calculate the performance measures of the new HRC network again. Otherwise, the conditions were satisfied, and then the results would be stored as new knowledge in the KBS.

In each iteration, the inputs of the simulation model are adjusted according to the recommendations provided by the rule-based inference engine. The simulator and rule-based inference engine exchange recently generated data until all satisfaction ranges of performance measures are achieved. In this way, the proposed HDSS finds the best HRC network configuration for each possible scenario and store the results in the knowledge base. Two levels of rules are provided as logistical and relief items' allocation rules in three segments including the event type, conditions and actions. All notations have been provided in nomenclature. The represented schemas for the logistical and relief items' allocation rules for managing $\mathrm{HRC}$ are as follows: 
Event type: The time tag part of the action rules that dictate the analysis of state must be done once an event has taken place. Time flag $\left(T F_{t}\right)$ is considered as the point where the system stops and checks the rules.

$$
T F_{t}=t
$$

Conditions: It includes a list of conditions. In order to start an action, all conditions should be satisfied. These conditions refer to logical assertions about the values of the HRCs' performance measures (3)-(6) calculated by the simulator.

- Relief items' allocation conditions:

$$
\begin{aligned}
& R S=\left[\sum_{z=1}^{Z} \sum_{n=1}^{N}\left(d_{n}^{z}-\sum_{i=1}^{I} \sum_{j=1}^{J} F_{i j n}^{z}\right)\right] / \sum_{z=1}^{Z} \sum_{n=1}^{N} d_{n}^{z} \notin\left[\Gamma^{-}, \Gamma^{+}\right] \\
& R E=\left[\sum_{z=1}^{Z} \sum_{n=1}^{N}\left(\sum_{i=1}^{I} \sum_{j=1}^{J} F_{i j n}^{z}-d_{n}^{z}\right)\right] / \sum_{z=1}^{Z} \sum_{n=1}^{N} d_{n}^{z} \notin\left[\Psi^{-}, \Psi^{+}\right] \\
& C^{L T}=\sum_{z=1}^{Z} \sum_{j=1}^{J} L_{j}^{z} \cdot C_{j z}^{L T} \notin\left[\Upsilon^{-}, \Upsilon^{+}\right] \\
& C^{C T}=\sum_{i=1}^{I} \theta_{i} \cdot C_{i}^{C T} \notin\left[\Delta^{-}, \Delta^{+}\right]
\end{aligned}
$$

- Logistical conditions:

$$
\begin{aligned}
C^{C o} & =\sum_{e=1}^{E} U_{e} E_{e}^{C o} \notin\left[\Lambda^{-}, \Lambda^{+}\right] \\
L T^{L T} & =\sum \sum \sum \sum F_{i j n}^{z} \cdot L T_{j}^{z} \notin\left[\mathrm{I}^{-}, \mathrm{I}^{+}\right] \\
L T^{C T} & =\sum_{n=1}^{N} \sum_{q=1}^{Q} \sum_{i=1}^{I} F_{q n i} . \theta_{i} \cdot L T_{i} \notin\left[\Phi^{-}, \Phi^{+}\right]
\end{aligned}
$$

Actions: This segment specifies an action that might include dispatching of relief items, selection of transportation modes, setting up extra LTs or CTs, etc.

$$
\begin{aligned}
& \left.\theta^{t}=\theta^{(t-1)} \pm \min \left\{\left(\Delta^{+}-C^{C T t} / C_{i}^{C T}\right),\left(\left(F_{q n i}^{t}-\sum_{n} \sum_{q} t \cdot \xi_{q n}^{H O}\right) / t \cdot \psi_{i n}^{C T}\right)\right)\right\} \wedge L^{t} \\
& L_{j}^{z t}=L_{j}^{z(t-1)} \pm \min \left\{\left(\Upsilon^{+} \cdot\left(\sum_{n=1}^{N} d_{n}^{z} / \sum_{z=1}^{Z} \sum_{n=1}^{N} d_{n}^{z}\right)-C_{z}^{L T t} / C_{j}^{L T z}\right),\left(\left(F_{i j n}^{z t}-t \cdot \sum_{i} \sum_{n} \xi_{i n}^{C T}\right) / t \cdot \psi_{j n}^{L T}\right)\right\} \wedge \hat{L}_{j}^{z t} \\
& F_{i j n}^{z t}=F_{i j n}^{z(t-1)} \pm \min \left\{\left(\Gamma^{+} \cdot\left(\sum_{n=1}^{N} d_{n}^{z} / \sum_{z=1}^{Z} \sum_{n=1}^{N} d_{n}^{z}\right)-F_{i j n}^{z(t-1)}\right), t \sum_{n} \xi_{j n}^{L T}\right\} \\
& F_{q n i}^{t}=F_{q n i}^{(t-1)} \pm \min \left\{\left(\Gamma^{+t} \cdot\left(\sum_{n=1}^{N} d_{n}^{z} / \sum_{z=1}^{Z} \sum_{n=1}^{N} d_{n}^{z}\right)-F_{q n i}^{(t-1)}\right), t \cdot \sum_{n} \xi_{i n}^{C T}\right\} \\
& v_{i e}^{q n t}: \sum_{n} \sum_{e} v_{i e}^{q n t} \cdot E_{e}^{c a}=F_{q n i}^{t} \wedge \sum_{q} \sum_{n} \sum_{e} v_{i e}^{q n t} \cdot L T_{i} \leq \Phi^{+t}
\end{aligned}
$$




$$
v_{i n e}^{z j}: \sum_{n} \sum_{e} v_{i n e}^{z j} \cdot U_{e} \cdot E_{e}^{c a}=F_{i j n}^{z} \wedge \sum_{j} \sum_{n} \sum_{e} v_{i n e}^{z j} \cdot L T_{j}^{z} \leq \mathrm{I}^{+t} \cdot\left(\sum_{n=1}^{N} d_{n}^{z} / \sum_{z=1}^{Z} \sum_{n=1}^{N} d_{n}^{z}\right)
$$

The interaction between the simulator and rule-based inference engine continues until all satisfaction ranges of performance measures are reached. Subsequently, the status of the zones and decision parameters (15-20) are recorded in separate databases and used by KBS. If the satisfaction ranges of the performance measures calculated by simulator are not achieved for a scenario, the proposed actions (i.e. equations (15)-(20)) generate a new network configuration. Equation (15) increases or decreases the number of CTs at the time flag $t$ in the network according to the satisfaction range of CTs' total setup cost and the capability of CTs in distributing the relief items. Equation (16) adds or removes LTs from each zone by considering satisfaction range of LTs' total setup cost and the distributed amount of relief items to LTs in zone $z$ from CTs. The amount of relief items that were allocated to LTs and CTs are modified by equations (17) and (18), respectively. These equations aim to minimize the shortage and excess amount of relief items by closing the distributed amount of relief items to their satisfaction ranges. Equations (19) and (20) determine the type and amount of transportation modes according to the amount of relief items distributed between CTs and LTs. Figure 2 shows the rules to be used for increasing and decreasing the number of CTs and LTs.

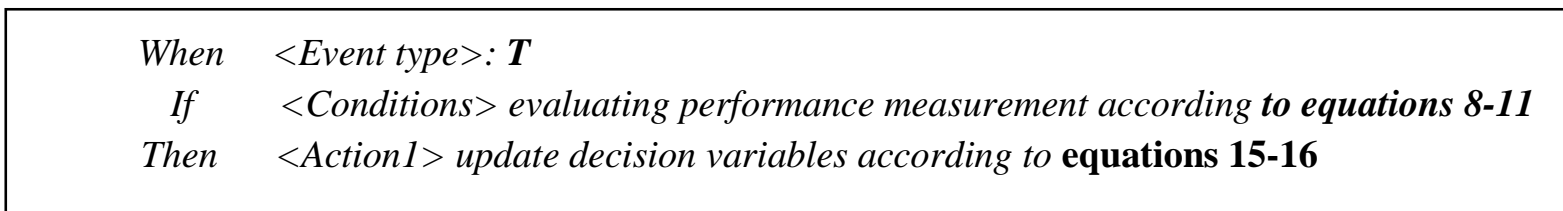

Figure 2. Rules for increasing and decreasing the number of CTs and LTs

Since rule-based simulation optimization technique can find the best configuration of the HRC according to preferences of decision makers, we use the lower and upper bounds as satisfaction levels for performance metrics. In this way, HRC managers can determine the most appropriate levels for the performance measures. Indeed, these levels are used as stopping criteria in simulation runs. Another reason for defining lower and upper bounds is the multi-objective nature of the proposed HRC model. For example, the LT is decreased as the TC increases. In the context of multi-objective programming, these bounds constitute the so-called positive ideal solution (PIS) and negative ideal solutions (NIS). While a performance measure gets closed to its PIS (for example the lower bound on the TC), another performance measure becomes closer to its NIS. In this paper, a configuration is accepted in which all performance measures fall within pre-defined satisfaction range. 


\subsubsection{Step4: HRC's network configuration forming}

The rule-based simulator finds the best configuration for each scenario. Now, the aim is to create and store the best network configuration for each scenario that was previously generated according to possible post-disaster situations. The appropriate network configurations that were known as knowledge can be retrieved by the KBS to manage the HRC in accordance with the real situations in the post-disaster phase. Notably, the KBS consists of different pairs of input parameters and their related best configurations that can be retrieved according to the real post-disaster situations.

\section{Case study: the HRC of Tehran}

In this section, the proposed HDSS framework is applied to design and evaluate Tehran HRC network against earthquake. Tehran, the capital of Iran, is prone to earthquakes whose vulnerability to earthquakes has been a living fact throughout the history. Adobe, masonry or traditional structures and urban fabrics that are highly vulnerable to earthquakes cover some parts of the city [57]. Furthermore, the city has been surrounded by several active faults and has experienced strong earthquakes in the past.

\subsection{Overview of the Tehran HRC}

Different criteria exist worldwide to study the vulnerability of urban fabrics and prioritizing them for improvement in earthquake-prone zones. Seismic and socioeconomic issues, land use considerations, structural and infrastructural situation, relation between sites and roads, building height-bulk-shape control, and restrictions in fire protection zones are considered as the urban fabric zoning criteria generally [58]. In this regards, Hosseini et al. [59] proposed three criteria as vulnerability of buildings, size of houses inside the blocks and width of existing road network in urban blocks to evaluate the earthquake potential damages in urban fabrics. They partitioned Tehran fabric into three zones as Priority Improvement Area (PIA), Improvement Area (IA) and Built-up Area (BA). PIA zones are the most vulnerable urban fabrics having many weak buildings and suffer from lack of sufficient evacuation places, evacuation roads and so on. IA zones are also high-risk places, which are expected to be damaged seriously by an earthquake. BA zones are characterized as not being vulnerable seriously and consist of proper buildings with good evacuation index.

To estimate the percentage vector of affected people in terms of injury levels $\left(\eta_{z}^{u}\right)$ under any earthquake scenario, we consider three indices as vulnerability of buildings and roads, evacuation conditions and secondary danger for each area [59]. Due to the lack of detailed information about vulnerability of buildings and roads, evacuation conditions and secondary danger for each area in the Tehran, we fit uniform continuous distributions for each element of this vector for each type of zones. To this end, we held several meetings with representative experts from Tehran Disaster Mitigation and Management Organization (http://tdmmo.tehran.ir). We asked them to identify zones types and 
percentage vector of affected people in terms of injury levels under any earthquake scenario. According to the zoning and geographical indices, we split urban areas of Tehran to seven zones. The location of candidate sites for setting up CTs are near the three major types of terminals including: airports (Imam Khomeini, Mehrabad and Galemorgi airports), train stations (Tehran rail station) and bus terminals (West, East, South and Beihaghi terminals). To determine the locations and types of LTs, they are classified into three classes including the medical, shelter and service terminals as follows:

- Medical LT (MLT): Facilities that could be setup for medical efforts, emergency care and medical treatment such as hospitals, medical centers, emergency wards and clinics;

- Shelter LT (SHLT): Temporary safe places for hosting those who have lost their houses such as hotels, schools, and public buildings;

- Service LT (SLT): Facilities for supplying relief items (e.g. food, water, emergency personnel, and firefighters). .

Hospitals, schools, hotels, emergency wards, clinics, and temporary shelters are samples of the potential LTs. Map of Tehran zones, candidate CTs and LTs shown in Appendix II schematically. We classify the HOs into two categories as internal and external HOs. Internal HOs are able to dispatch relief items via local railroads or truck roads while external HOs are those that need air transport to dispatch their relief items. In order to implement the proposed HDSS for Tehran, the experimental data was collected from Tehran Municipality web site [58] and Iran Statistics Information center [60]. As mentioned above, eight CTs are considered for Tehran. The name, location, available transportation mode, input and output rates and the capacity of these terminals are extracted from different sources (such as Municipality of Tehran reports, Terminals and Airport web sites). Input and output rates along with the capacity of CTs were estimated according to the terminals' areas, capacity of depots, filler and railhead depot, storage capacity, terminal personal input and output commodities and storage capacity for a year (details can be provided upon request of any interested reader). Tehran has 22 regions as defined by the Municipality. Based on the available facilities in these regions, accessibility of roads and population, Tehran municipality has setup a number of medical, shelter and service LTs in each zone. Different types of transportation modes are needed to distribute relief items. We consider three kinds of transportation modes for transporting relief items between HOs and CTs. In the meantime, two transportation modes could be used for transferring between CTs and LTs including helicopters and trucks. Experts of Tehran Disaster Mitigation and Management Organization identify five kinds of relief items including water/food, shelter, drugs, and medicine team.

The pseudo code of the proposed HDSS is presented in Appendix I. It was coded in MATLAB and executed on a Pentium $3.2 \mathrm{GHz}$ under Windows XP using $1 \mathrm{~GB}$ of RAM. By considering three 
factors as population density (PD), earthquake magnitudes (EF), and Ways and building destruction percentage, 27 scenarios are generated. In the first scenario, we consider an earthquake at 4 Richter with building destruction rate of more than $50 \%$. In the two other scenarios, we set the earthquake magnitudes between 4 and 6 and more than 6 Richter with destruction rates for routes and buildings at less and more than 50\% respectively. In addition, the population densities for each scenario are under 50, between 50 and 100 and more than 100 people per Hectare. Percentage of affected people with different injury levels in different zones were randomly generated under different scenarios. The demand of each relief item in each zone was calculated by equation (2) and the related results were summarized in Table 1. The execution was stopped at four-time with time interval 6 hours. The number of established CTs and LTs and the amounts of the performance measures for each scenario are summarized in Table 2.

\subsection{Results and discussion}

The proposed HDSS was run for 4000 times based on 27 scenarios in 24 hours. Then, the average performance measures are normalized and shown in Figure 3. As seen in the figure, during the first six hours after the earthquake, the total relief items' shortage (RS) and the total lead-time (LT) is high while the total cost (TC) is low.

Table 1. Demand of each relief item in each zone

\begin{tabular}{|c|c|c|c|c|c|c|c|}
\hline \multirow[b]{2}{*}{ Scenario } & \multirow[b]{2}{*}{ Zone } & \multicolumn{6}{|c|}{ Relief item } \\
\hline & & Water/food & shelter & drugs & Medicine team & Miscellaneous items & Total \\
\hline \multirow[t]{8}{*}{ Scenario 1} & $\mathrm{Z} 1$ & 5164931 & 6252285 & 5232891 & 5096972 & 5029012 & 26776092 \\
\hline & $\mathrm{Z} 2$ & 12684134 & 13808045 & 9954637 & 9633520 & 11399665 & 57480001 \\
\hline & $\mathrm{Z3}$ & 2254655 & 2031667 & 916727.9 & 619410.8 & 1461809 & 7284270.5 \\
\hline & $\mathrm{Z} 4$ & 22364959 & 20153040 & 9093445 & 6144220 & 14500358 & 72256021 \\
\hline & Z5 & 8053259 & 7256783 & 3274402 & 2212434 & 5221344 & 26018221 \\
\hline & Z6 & 14250894 & 17251082 & 14438406 & 14063382 & 13875870 & 73879635 \\
\hline & $\mathrm{Z7}$ & 3685444 & 4012002 & 2892374 & 2799071 & 3312235 & 16701126 \\
\hline & Total & 68458277 & 70764905 & 45802882 & 40569009 & 54800293 & 280395366 \\
\hline \multirow[t]{8}{*}{ Scenario 2} & $\mathrm{Z} 1$ & 6197917 & 7502742 & 6279469 & 6116366 & 6034814 & 32131310 \\
\hline & $\mathrm{Z} 2$ & 15220960 & 16569654 & 11945564 & 11560224 & 13679598 & 68976001 \\
\hline & $\mathrm{Z3}$ & 2705586 & 2438000 & 1100073 & 743292 & 1754170 & 8741124 \\
\hline & $\mathrm{Z} 4$ & 26837950 & 24183648 & 10912134 & 7373064 & 17400429 & 86707225 \\
\hline & $\mathrm{Z} 5$ & 9663910 & 8708139 & 3929282 & 2654920 & 6265612 & 31221865 \\
\hline & Z6 & 17101072 & 20701298 & 17326087 & 16876058 & 16651044 & 88655562 \\
\hline & $\mathrm{Z7}$ & 4422532 & 4814402 & 3470848 & 3358885 & 3974682 & 20041351 \\
\hline & Total & 82149932 & 84917886 & 54963458 & 48682810 & 65760351 & 336474439 \\
\hline \multirow[t]{8}{*}{ Scenario 3} & $\mathrm{Z} 1$ & 7024306 & 8503107 & 7116731 & 6931881 & 6839456 & 36415485 \\
\hline & $\mathrm{Z} 2$ & 17250422 & 18778941 & 13538306 & 13101587 & 15503544 & 78172801 \\
\hline & $\mathrm{Z} 3$ & 3066330 & 2763067 & 1246749 & 842398 & 1988060 & 9906607 \\
\hline & $\mathrm{Z} 4$ & 30416344 & 27408134 & 12367085 & 8356139 & 19720486 & 98268188 \\
\hline & $\mathrm{Z} 5$ & 10952432 & 9869224 & 4453186 & 3008910 & 7101027 & 35384780 \\
\hline & Z6 & 19381215 & 23461471 & 19636232 & 19126199 & 18871183 & 100476303 \\
\hline & $\mathrm{Z7}$ & 5012203 & 5456322 & 3933628 & 3806736 & 4504639 & 22713531 \\
\hline & Total & 93103256 & 96240270 & 62291919 & 55173852 & 74528398 & 381337697 \\
\hline
\end{tabular}

By activating extra CTs and LTs in the next 18 hours, the shortage ratio is decreased significantly while the total cost is increased. Although the number of established CTs and LTs are increased and more transportation equipment needs to be available, the total lead-time was not reduced as expected. 
To decrease the total lead-time of relief chain that is known as the main challenge by many relief chain managers, we set an upper bound for the total lead-time and run the HDSS again.

Table 2. The number of established CTs and LTs and corresponding performance measures

\begin{tabular}{llcccccccc}
\hline \multirow{2}{*}{ Scenario } & \multirow{2}{*}{ Time flag } & \multirow{2}{*}{ CT } & \multicolumn{9}{c}{ LT } & \multirow{2}{*}{ RS } & \multirow{2}{*}{ RE } & TC & \multirow{2}{*}{ LT } \\
\cline { 4 - 7 } & & & MLT & SHLT & SLT & & & & \\
\hline S1 & $\mathrm{T}=6$ & 2 & 474 & 653 & 944 & 0.878 & - & 56644 & 1.125 \\
& $\mathrm{~T}=12$ & 5 & 1373 & 995 & 1648 & 0.775 & - & 106175 & 1.069 \\
& $\mathrm{~T}=18$ & 6 & 2497 & 1849 & 3264 & 0.599 & - & 190458 & 1.000 \\
& $\mathrm{~T}=24$ & 8 & 4296 & 3215 & 4865 & 0.360 & - & 302499 & 0.974 \\
\hline S2 & $\mathrm{T}=6$ & 3 & 609 & 924 & 1270 & 0.868 & - & 73898 & 1.075 \\
& $\mathrm{~T}=12$ & 5 & 1688 & 1234 & 2287 & 0.763 & - & 134298 & 1.041 \\
& $\mathrm{~T}=18$ & 6 & 3037 & 2259 & 4321 & 0.583 & - & 237729 & 0.993 \\
& $\mathrm{~T}=24$ & 8 & 5195 & 3899 & 6356 & 0.348 & - & 374610 & 0.967 \\
\hline S3 & $\mathrm{T}=6$ & 4 & 717 & 1183 & 1736 & 0.852 & - & 94148 & 1.056 \\
& $\mathrm{~T}=12$ & 6 & 1940 & 1736 & 2986 & 0.741 & - & 167146 & 1.010 \\
& $\mathrm{~T}=18$ & 6 & 3469 & 3219 & 5486 & 0.547 & - & 293181 & 0.966 \\
& $\mathrm{~T}=24$ & 8 & 5915 & 5332 & 7986 & 0.295 & - & 458691 & 0.952 \\
\hline
\end{tabular}

As shown in Figure 4, although the total lead-time is decreased, the total cost of relief chain is increased significantly as a result of increased number of established LTs.

The results of the rule-based simulation module show the trend of three performance measures during the first $6,12,18$ and 24 hours after the simulated earthquake. Now, the HRC managers can set the desired preparedness level and answer many questions such as how much relief items should be stored and where? and how many LTs and CTs must be setup and where? By applying the proposed approach, they can evaluate the outcomes of their decisions in the simulated post-disaster phase. Part of the obtained knowledge for the three sample scenarios is summarized in Table 3.

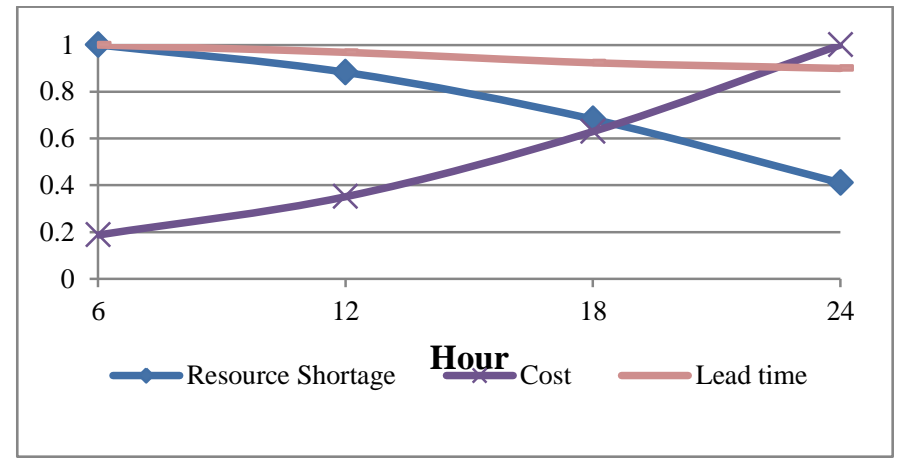

Figure 3. Performance measurement of Tehran's HRC during the first 24 hours after an earthquake 


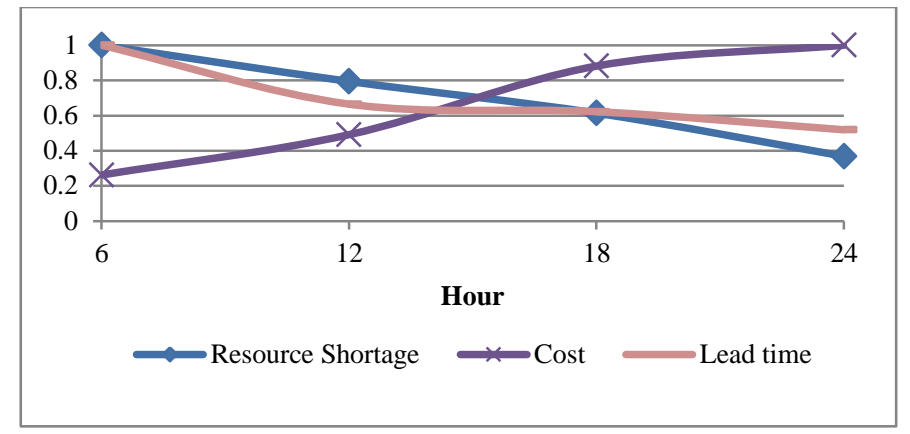

Figure 4. Performance measurement of Tehran's HRC with a maximum lead-time as the first 24 hours after an earthquake

\subsection{Comparison with existing HRC network in Tehran}

To evaluate the performance of the proposed HDSS, we compare the obtained results with the data related to the existing HRC network in Tehran (named as "existing configuration"). In the existing configuration, 1986, 1827 and 1710 LTs of types MLT, SHLT and SLT have been identified, respectively. Notwithstanding, the HDSS proposes setting up different numbers of LTs based on the response horizon. To interpret this variation, the number of required LTs under scenarios 1 and 27 are compared with the existing configuration. The variation of SHLTs, MLTs and SLTs proposed by the HDSS under scenarios 1 and 27 and the existing configuration (see Table 3) are illustrated via Figures 5 to 7 , respectively. As these figures show, the number of LTs is fixed in the existing configuration while the number of setup LTs by HDSS are increased along the relief operations at post-disaster. The performance of the proposed HDSS network and existing configuration is comprised at [6-12], [1218], and [18-24] hours after an earthquake.

Table 3. Extracted knowledge for the three sample scenarios

\begin{tabular}{|c|c|c|c|c|c|c|c|c|c|c|c|c|c|c|}
\hline \multirow{3}{*}{$\mathrm{S}$} & \multirow{3}{*}{$\begin{array}{c}\text { PT } \\
1\end{array}$} & \multicolumn{7}{|c|}{ IF } & \multicolumn{6}{|c|}{ Then } \\
\hline & & \multirow[t]{2}{*}{ PD } & $\mathrm{E}$ & WB & \multirow[t]{2}{*}{$\mathrm{RS}$} & \multirow{2}{*}{$\begin{array}{l}\mathrm{R} \\
\mathrm{E}\end{array}$} & \multirow[t]{2}{*}{ TC } & \multirow[t]{2}{*}{ BT } & \multirow{2}{*}{$\begin{array}{l}\text { CT } \\
\mathrm{s}\end{array}$} & \multirow{2}{*}{$\begin{array}{l}\mathrm{ML} \\
\mathrm{T}\end{array}$} & \multirow{2}{*}{$\begin{array}{l}\text { SHL } \\
\text { T }\end{array}$} & \multirow{2}{*}{$\begin{array}{l}\text { SL } \\
\mathrm{T}\end{array}$} & \multirow[t]{2}{*}{$\mathrm{F}^{2}$} & \multirow[t]{2}{*}{$\mathrm{Ne}^{3}$} \\
\hline & & & F & D & & & & & & & & & & \\
\hline \multirow[t]{8}{*}{1} & 6 & -50 & -5 & -50 & 0.87 & - & 56644 & 1.12 & 2 & 474 & 653 & 944 & 34.2 & 119 \\
\hline & & & & & 8 & & & 5 & & & & & & 9 \\
\hline & 12 & & & & 0.77 & - & 10617 & 1.06 & 5 & 1373 & 995 & 164 & 62.9 & 110 \\
\hline & & & & & 5 & & 5 & 9 & & & & 8 & 7 & 9 \\
\hline & 18 & & & & 0.59 & - & 19045 & 1.00 & 6 & 2497 & 1849 & 326 & 112. & 130 \\
\hline & & & & & 9 & & 8 & 0 & & & & 4 & 3 & 8 \\
\hline & 24 & & & & 0.36 & - & 30249 & 0.97 & 8 & 4296 & 3215 & 486 & 176. & 153 \\
\hline & & & & & 0 & & 9 & 4 & & & & 5 & 8 & 3 \\
\hline \multirow[t]{4}{*}{2} & 6 & $50-$ & $5-$ & +50 & 0.86 & - & 73898 & 1.07 & 3 & 609 & 924 & 127 & 44.2 & 138 \\
\hline & & 100 & 7 & & 8 & & & 5 & & & & 0 & 1 & 5 \\
\hline & 12 & & & & 0.76 & - & 13429 & 1.04 & 5 & 1688 & 1234 & 228 & 79.5 & 153 \\
\hline & & & & & 3 & & 8 & 1 & & & & 7 & 3 & 3 \\
\hline
\end{tabular}




\begin{tabular}{|c|c|c|c|c|c|c|c|c|c|c|c|c|c|c|}
\hline & \multirow[t]{2}{*}{18} & & & & 0.58 & - & 23772 & 0.99 & 6 & 3037 & 2259 & 432 & 140. & 161 \\
\hline & & & & & 3 & & 9 & 3 & & & & 1 & 1 & 7 \\
\hline & \multirow[t]{2}{*}{24} & & & & 0.34 & - & 37461 & 0.96 & 8 & 5195 & 3899 & 635 & 219. & 188 \\
\hline & & & & & 8 & & 0 & 7 & & & & 6 & 1 & 6 \\
\hline \multirow[t]{8}{*}{3} & 6 & +10 & +7 & +50 & 0.85 & - & 94148 & 1.05 & 4 & 717 & 1183 & 173 & 56.3 & 170 \\
\hline & & 0 & & & 2 & & & 6 & & & & 6 & 5 & 5 \\
\hline & 12 & & & & 0.74 & - & 16714 & 1.01 & 6 & 1940 & 1736 & 298 & 98.7 & 193 \\
\hline & & & & & 1 & & 6 & 0 & & & & 6 & 2 & 8 \\
\hline & 18 & & & & 0.54 & - & 29318 & 0.96 & 6 & 3469 & 3219 & 548 & 172. & 197 \\
\hline & & & & & 7 & & 1 & 6 & & & & 6 & 5 & 7 \\
\hline & 24 & & & & 0.29 & - & 45869 & 0.95 & 8 & 5915 & 5332 & 798 & 268. & 229 \\
\hline & & & & & 5 & & 1 & 2 & & & & 6 & 6 & 8 \\
\hline
\end{tabular}

${ }^{1}$ Passed time after earthquake (hours); ${ }^{2}$ : Distributed relief items into the affected area (million); ${ }^{3}$ The number of needed transportation mode $e$ between CT and LT,

In the first 12 hours, the average number of LTs that were setup by existing configuration is more than or equal to the number of LTs that was set up by the HDSS. Although, more LTs have been setup in the existing configuration in the first 12 hours, the RS and BT measures are comparable to HDSS configuration. Since the amount of available relief items were not equal to the capacity of setup LTs in the first [6-12], the RS and BT are comparable (Table 4). Furthermore, the TC of the existing network is more than that of HDSS configuration in the first [6-12] (under scenario 1: TC of the existing configuration is 145646 and the TC of the HDSS is 81409). By increasing the amount of available relief items in the next 6 hours (i.e. [12-18], the average number of LTs is increased in HDSS. While in the existing configuration, numbers of the LTs are fixed. As reported in Table 4, the RS and BT of HDSS are decreased and TC is increased through [12-24] hours at post-disaster. It should be noted that arranging extra LTs in the first 12 hours not only increased the setup cost but also decreased the efficiency of the HRC. The reason behind this is that the quantities of relief items are not sufficient to fulfill the needs of existing configuration of LTs. From another point of view, extra LTs have been setup in the existing configuration while enough relief items are not available for HRC's operations. Indeed, the number of LTs should be increased after the first 12 hours upon the arrival of relief items in large quantities. For this reason, the HDSS increases the number of LTs at this period significantly, which decreases the level of lead-time. In the existing configuration, by fixing the number of active LTs, the amount of total shortage and total lead-time of relief operations are increased considerably. Consequently, HRC managers should setup or activate more LTs along the planning horizon because the number of LTs affects the performance of the HRC. Excessive LTs increase the cost whilst insufficient LTs increase the total shortage of relief items and the total leadtime of relief operations. 
Table 4. The comparative study of HDSS and existing configuration under scenarios 1 and 27

\begin{tabular}{|c|c|c|c|c|c|c|c|c|c|c|c|c|c|}
\hline \multirow{2}{*}{$\begin{array}{l}S \\
1\end{array}$} & \multirow{2}{*}{$\underset{2}{\mathbf{P T}}$} & \multicolumn{2}{|c|}{$\mathbf{R S}$} & \multicolumn{2}{|c|}{ TC } & \multicolumn{2}{|c|}{ BT } & \multicolumn{2}{|c|}{ MLT } & \multicolumn{2}{|c|}{ SHLT } & \multicolumn{2}{|c|}{ SLT } \\
\hline & & $\begin{array}{c}\mathrm{HDS} \\
\mathrm{S}\end{array}$ & $\mathrm{EC}^{3}$ & $\begin{array}{c}\text { HDS } \\
\text { S }\end{array}$ & $\mathrm{EC}$ & $\begin{array}{c}\text { HDS } \\
\text { S }\end{array}$ & $\mathrm{EC}$ & $\begin{array}{c}\text { HDS } \\
\text { S }\end{array}$ & $\overline{\mathrm{EC}}$ & $\begin{array}{c}\text { HDS } \\
\text { S }\end{array}$ & $\overline{\mathrm{EC}}$ & $\begin{array}{c}\text { HDS } \\
\text { S }\end{array}$ & $\overline{\mathrm{EC}}$ \\
\hline \multirow[t]{8}{*}{1} & {$[6-$} & 0.82 & 0.79 & 81409 & 14564 & 1.09 & 0.97 & 923 & 198 & 824 & 182 & 1296 & 171 \\
\hline & 12] & 6 & 5 & & 6 & 7 & 2 & & 6 & & 7 & & 0 \\
\hline & {$[12$} & 0.68 & 0.69 & 14831 & 14564 & 1.03 & 1.01 & 1935 & 198 & 1422 & 182 & 2456 & 171 \\
\hline & - & 7 & 0 & 6 & 6 & 4 & 6 & & 6 & & 7 & & 0 \\
\hline & 18] & & & & & & & & & & & & \\
\hline & [18 & 0.47 & 0.63 & 24647 & 14564 & 0.98 & 1.14 & 3396 & 198 & 2532 & 182 & 4064 & 171 \\
\hline & - & 9 & 8 & 8 & 6 & 7 & 0 & & 6 & & 7 & & 0 \\
\hline & 24] & & & & & & & & & & & & \\
\hline 2 & [6- & 0.81 & 0.80 & 10409 & 14564 & 1.05 & 0.97 & 1328 & 198 & 1459 & 182 & 2361 & 171 \\
\hline \multirow[t]{7}{*}{7} & 12] & 5 & 5 & 8 & 6 & 8 & 3 & & 6 & & 7 & & 0 \\
\hline & {$[12$} & 0.67 & 0.74 & 18601 & 14564 & 1.01 & 1.02 & 2704 & 198 & 2477 & 182 & 4236 & 171 \\
\hline & - & 3 & 2 & 3 & 6 & 7 & 5 & & 6 & & 7 & & 0 \\
\hline & 18] & & & & & & & & & & & & \\
\hline & {$[18$} & 0.46 & 0.75 & 30619 & 14564 & 0.98 & 1.10 & 4692 & 198 & 4275 & 182 & 6736 & 171 \\
\hline & - & 5 & 1 & 6 & 6 & & 3 & & 6 & & 7 & & 0 \\
\hline & 24] & & & & & & & & & & & & \\
\hline
\end{tabular}

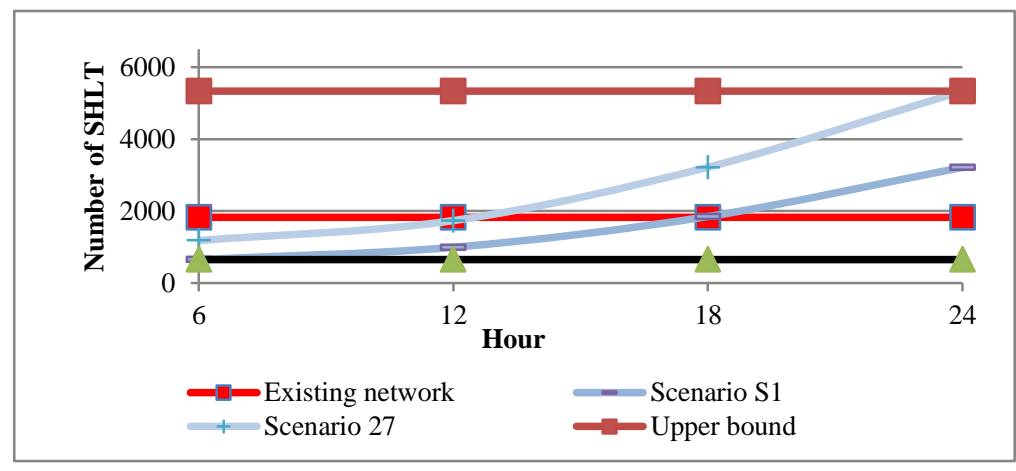

Figure 5. The variation of SHLT between existing configuration and scenarios 1 and 27 of proposed HDSS

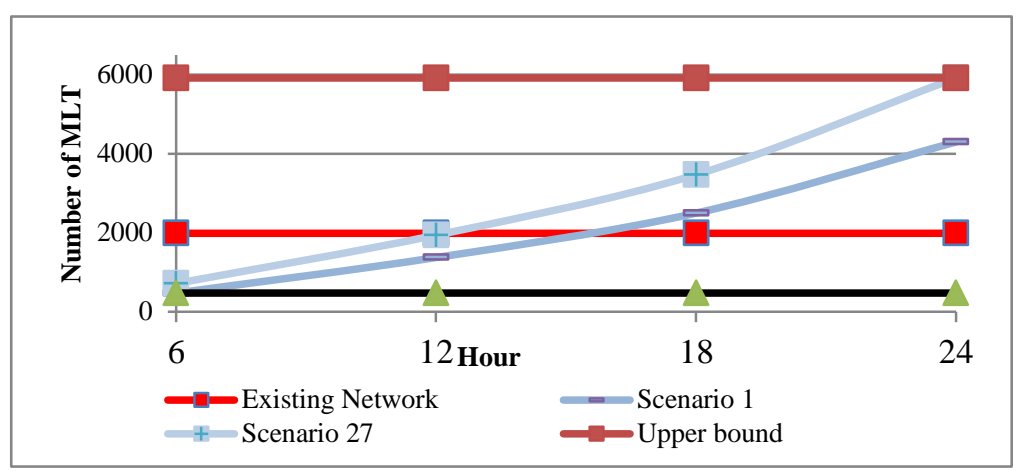

Figure 6. The variation of MLT between existing configuration and scenarios 1 and 27 of proposed HDSS 


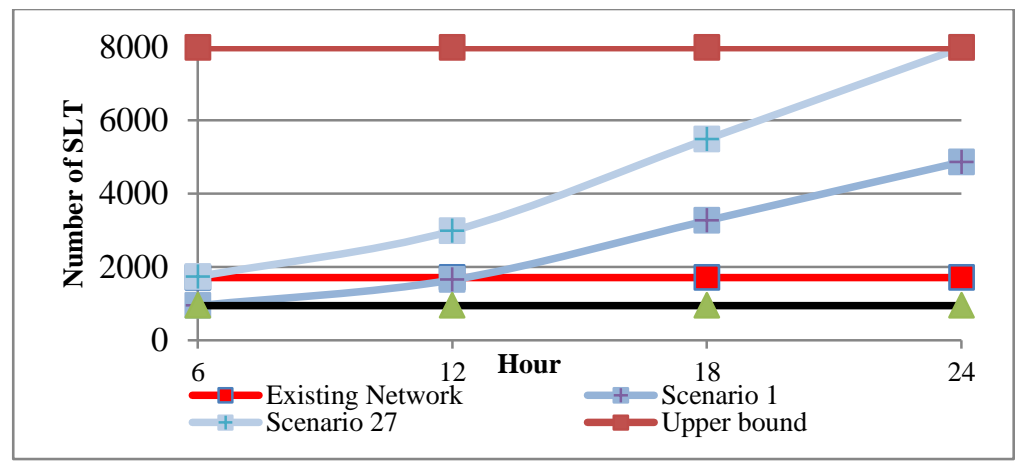

Figure 7. The variation of SLT between existing configuration and scenarios 1 and 27 of proposed HDSS

\subsection{Implications for HRC managers of Tehran}

The outcomes of the HDSS can assist local authorities in making informed decisions about the proper configuration of the required HRC network and evaluating the performance of the configured HRC based on the performance measures. Figure 8 show the impact of HDSS on HRC in comparison with the existing configuration according to the two performance measures (i.e. the total cost and the available relief items that can be delivered to affected people at post-disaster). Horizontal and vertical vectors show the time and total HRC cost and available relief items, schematically. According to the IFRC report cited in [44], HRC managers often spend limited budget at pre-disaster to mitigate the impact of possible disasters. Nonetheless, the existing configuration of the HRC for Tehran suffers from lack of required relief items to deal with no-notice large-scale earthquakes. In the proposed HDSS and by evaluating various disaster scenarios before their occurrence, an effective HRC could be configured efficiently and continuously. To clarify this issue, we compare the cost and available relief items of the proposed HRC with the existing configuration at the different response horizons. HRCs' cost and available relief items might be increased or decreased throughout the preparedness and response phases as shown in Figure 8. The main difference between the configuration offered by the proposed HDSS and the existing configuration is shown as the slope of both HRC cost and the amount of available relief items. In pre-disaster phase, the local authorities of Tehran allocate a specific budget to configure the HRC. After an earthquake, relief procurement and donations are suddenly increased and large amounts of relief items are dispatched to the affected areas. At this time, the HRC managers might spend a lot of money to configure an enhanced HRC for running relief operations. Nevertheless, they would lose a part of donations and procured items due to lack of capacity of existing HRC network configuration.

Undoubtedly, continuous improvement of performance of the HRC network under different scenarios increases the HRC cost in order to setup more CTs and LTs significantly. The HRC network of existing configuration leaves many affected people in the affected areas at the early response phase. The sharp slope of existing HRC cost in the early response phase shows this issue (black line). In comparison with the existing configuration, the cost of the HDSS is increased mildly (i.e. the red 
dotted line) during the pre-disaster phase under different scenarios. Increasing the performance measures of the HRC network in pre-disaster phase continuously leads to an increase in the amount of available relief items for distributing among affected people. Therefore, the gradient of the blue dash line is sharpening more than the green dash dotted one in the response phase. Finally, by decreasing the demand of relief item at the recovery phase, the available resources go back to their initial amount (see figure 8). In fact, the amounts of relief item demand that are needed for helping affected people determine the demarcation of each disaster operation lifecycle.

Similar to the total cost, the amount of HRC resources suggested by the HDSS in the CTs is different compared to the existing configuration. Usually, HRC managers store some amounts of relief items for early response phase according to their budget (referred to as available resource level). Due to unpredictable situation in the post-disaster phase, the HRC might face with considerable shortage. The sharp gradient of the proposed HDSS resource level in the post disaster phase (i.e. the blue dash line) compared to the mild gradient of the existing configuration (i.e. the green dash dotted line) shows this issue. It should be noted that the main difference between the HDSS and existing configuration based on the HRC resources is the time that the HRC resources reach their picks. Since the HDSS was trained under different scenarios at the pre-disaster phase, it could arrive to the maximum point faster than the existing configuration.

Due to the nature of the disaster and HRC networks, the HRC managers should improve the configured network continuously during the pre-disaster phase. They can configure an initial HRC network and then allocate more budget for increasing the number of CTs, LTs, and the amount of stored relief items. In this way, they can define different scenarios and find the best configuration for each one. Furthermore, implementation periods should be considered for the different scenarios. For example, HRC managers can provide the relief items and setup a number of the CTs and LTs according to the best configuration corresponding to the first scenario within the first six months. In the next six months, the HRC network could be improved according to the second scenario. In this manner, HRC managers can improve the performance measures of the configured HRC gradually. The proposed HDSS has the capability of finding the best configuration under each scenario in predisaster phase by simulating the probable post-disaster situations. This issue is one of the main advantages of the proposed DSS. As Figure 8 shows, the amount of relief items in which, the cost of configured HRC is not fixed in pre-disaster phase. By improving the HRC network in pre-disaster phase, the capability of the configured network would be increased in post-disaster phase. 


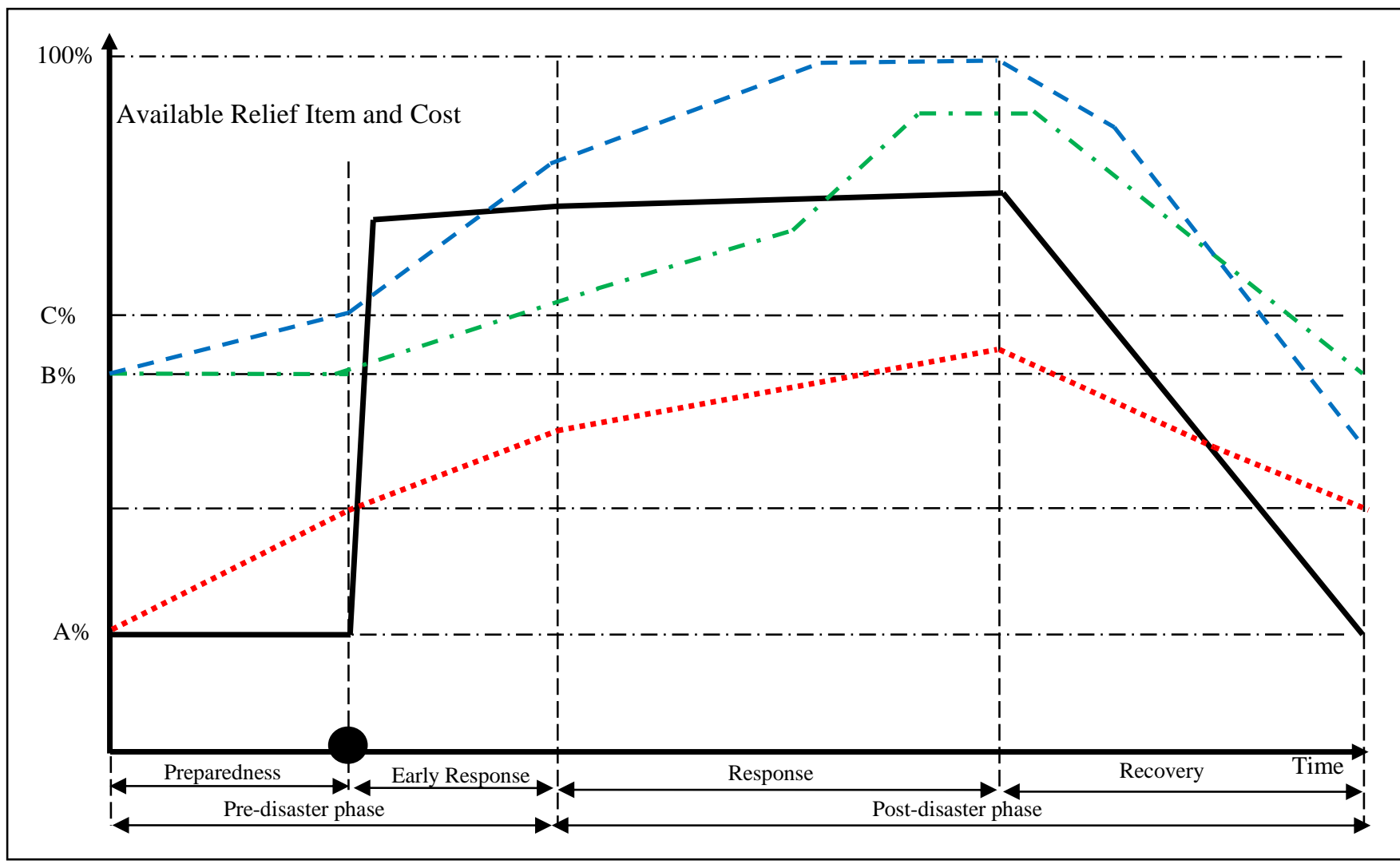

Figure 8. Impact of proposed HDSS in comparison with the existing configuration (Red dotted line: HRC Cost of HDSS; Black line: HRC Cost of existing configuration; Blue dash line: HRC Resource of HDSS; Green dash dotted line: HRC Resource of existing configuration

\section{Conclusion}

Due to the occurrence of several no-notice disasters either natural or man-made all over the world, quick response to the urgent needs of the affected areas right after a disaster is a critical issue for effective management of HRCs. In this paper, a HDSS consisting of a KBS and a rule-based simulator was developed to manage a three level HRC that includes multiple HOs, CTs and LTs. The rule-based simulator seeks for the satisfactory decisions by simulating the post-disaster scenarios in the predisaster phase through applying a rule-based system. Subsequently, the KBS is formed step-by-step based on the results of the rule-based simulator. To manage relief operations in unpredictable and complicated situations quickly and effectively, the proposed HDSS was equipped by some key features including particularity, self-assessment, training capability, generalization, and bi-phase structure. In addition, to evaluate the configured HRC, three main performance measures including the coverage, total cost, and response time were defined. Application of the proposed HDSS was demonstrated through a case study in Tehran during the preparedness phase to respond to potential earthquakes. The results show the usefulness and capability of the proposed HDSS for managing relief operation in an effective and timely manner by configuring a suitable HRC. Results of the case 
study shown that, HRC managers could improve the HRC configuration in pre-disaster phase by improving satisfaction of proposed HDSS. Due to different limitations in the affected area such as the infrastructures, vulnerable urban fabrics, and budget, HRC managers could significantly improve the HRC network based upon the results of proposed HDSS by improving satisfaction range of performance measures.

Future research could explore the use of fuzzy rule-based inference mechanisms for finding the more real configurations by introducing the epistemic uncertainty in input data. Noteworthy, consideration of epistemic uncertainty arisen from linguistic data can lead to better configurations. In addition, Reinforcement Learning technique could be combined with knowledge base systems to find satisfactory decisions by interacting with simulation core successively. Finally, using more performance measures to improve the evaluation process of each configured $\mathrm{HRC}$ involving several egalitarian and utilitarian measures is of vital importance.

\section{References}

[1] FritzInstitute, Logistics and the Effective Delivery of Humanitarian Relief, 2005.

[2] J.V. Florez, M. Lauras, U. Okongwu, L. Dupont, A decision support system for robust humanitarian facility location, Engineering Applications of Artificial Intelligence, 46 (2015) 326-335.

[3] J.A. Paul, L. MacDonald, Location and capacity allocations decisions to mitigate the impacts of unexpected disasters, European Journal of Operational Research, 251 (2016) 252-263.

[4] S. Tofighi, S. Torabi, S. Mansouri, Humanitarian logistics network design under mixed uncertainty, European Journal of Operational Research, 250 (2016) 239-250.

[5] J. Chacko, L.P. Rees, C.W. Zobel, T.R. Rakes, R.S. Russell, C.T. Ragsdale, Decision support for long-range, community-based planning to mitigate against and recover from potential multiple disasters, Decision Support Systems.

[6] S.-y. Roh, H.-m. Jang, C.-h. Han, Warehouse Location Decision Factors in Humanitarian Relief Logistics, The Asian Journal of Shipping and Logistics, 29 (2013) 103-120.

[7] H. Pateman, K. Hughes, S. Cahoon, Humanizing Humanitarian Supply Chains: A Synthesis of Key Challenges, The Asian Journal of Shipping and Logistics, 29 (2013) 81-102.

[8] D.K. Yadav, A. Barve, Analysis of critical success factors of humanitarian supply chain: An application of Interpretive Structural Modeling, International Journal of Disaster Risk Reduction, 12 (2015) 213-225.

[9] N. Ploskas, I. Athanasiadis, J. Papathanasiou, N. Samaras, A collaborative spatial decision support system for the capacitated vehicle routing problem on a tabletop display, Decision Support Systems IV-Information and Knowledge Management in Decision Processes, Springer2015, pp. 26-36.

[10] J.I. Kim, J. Kim, M. Fischer, R. Orr, BIM-based decision-support method for master planning of sustainable large-scale developments, Automation in Construction, 58 (2015) 95-108.

[11] N. Sahebjamnia, R. Tavakkoli-Moghaddam, N. Ghorbani, Designing a fuzzy Q-learning multiagent quality control system for a continuous chemical production line - A case study, Computers \& Industrial Engineering, 93 (2016) 215-226.

[12] W.J. Gutjahr, P.C. Nolz, Multicriteria optimization in humanitarian aid, European Journal of Operational Research, (2015).

[13] B. Balcik, B.M. Beamon, C.C. Krejci, K.M. Muramatsu, M. Ramirez, Coordination in humanitarian relief chains: Practices, challenges and opportunities, International Journal of Production Economics, 126 (2010) 22-34.

[14] G. Kabra, A. Ramesh, K. Arshinder, Identification and prioritization of coordination barriers in humanitarian supply chain management, International Journal of Disaster Risk Reduction, 13 (2015) 128-138. 
[15] D. Fogli, G. Guida, Knowledge-centered design of decision support systems for emergency management, Decision Support Systems, 55 (2013) 336-347.

[16] C. Fang, F. Marle, A simulation-based risk network model for decision support in project risk management, Decision Support Systems, 52 (2012) 635-644.

[17] S.H. Melouk, N.K. Freeman, D. Miller, M. Dunning, Simulation optimization-based decision support tool for steel manufacturing, International Journal of Production Economics, 141 (2013) 269276.

[18] B. Wolshon, "one-way-out": contraflow freeway operation for hurricane evacuation, Natural hazards review, 2 (2001) 105-112.

[19] N. Sahebjamnia, S.A. Torabi, S.A. Mansouri, Integrated business continuity and disaster recovery planning: Towards organizational resilience, European Journal of Operational Research, 242 (2015) 261-273.

[20] Y.-C. Chiu, H. Zheng, Real-time mobilization decisions for multi-priority emergency response resources and evacuation groups: model formulation and solution, Transportation Research Part E: Logistics and Transportation Review, 43 (2007) 710-736.

[21] S. Tufekci, W. Wallace, Emerging area of emergency management and engineering, IEEE Transactions on Engineering Management, 45 (1998) 103-105.

[22] A.M. Caunhye, X. Nie, S. Pokharel, Optimization models in emergency logistics: A literature review, Socio-Economic Planning Sciences, 46 (2012) 4-13.

[23] G. Galindo, R. Batta, Review of recent developments in OR/MS research in disaster operations management, European Journal of Operational Research, 230 (2013) 201-211.

[24] F. He, J. Zhuang, Balancing pre-disaster preparedness and post-disaster relief, European Journal of Operational Research, (2016).

[25] W.J. Gutjahr, A. Pichler, Stochastic multi-objective optimization: a survey on non-scalarizing methods, Annals of Operations Research, (2013) 1-25.

[26] T.R. Rakes, J.K. Deane, L.P. Rees, G.M. Fetter, A decision support system for post-disaster interim housing, Decision Support Systems, 66 (2014) 160-169.

[27] F. Liberatore, C. Pizarro, C.S. de Blas, M. Ortuño, B. Vitoriano, Uncertainty in humanitarian logistics for disaster management. A review, Decision aid models for disaster management and emergencies, Springer2013, pp. 45-74.

[28] Y. Kristianto, A. Gunasekaran, P. Helo, M. Sandhu, A decision support system for integrating manufacturing and product design into the reconfiguration of the supply chain networks, Decision Support Systems, 52 (2012) 790-801.

[29] S. Fazi, J.C. Fransoo, T. Van Woensel, A decision support system tool for the transportation by barge of import containers: A case study, Decision Support Systems, 79 (2015) 33-45.

[30] E. Ursavas, A decision support system for quayside operations in a container terminal, Decision Support Systems, 59 (2014) 312-324.

[31] A. Valluri, D.C. Croson, Agent learning in supplier selection models, Decision Support Systems, 39 (2005) 219-240.

[32] T.-M. Choi, J. Li, Y. Wei, Will a supplier benefit from sharing good information with a retailer?, Decision Support Systems, 56 (2013) 131-139.

[33] Z. Hong, C.K.M. Lee, A decision support system for procurement risk management in the presence of spot market, Decision Support Systems, 55 (2013) 67-78.

[34] J. Scott, W. Ho, P.K. Dey, S. Talluri, A decision support system for supplier selection and order allocation in stochastic, multi-stakeholder and multi-criteria environments, International Journal of Production Economics, 166 (2015) 226-237.

[35] B. Van de Walle, M. Turoff, Decision support for emergency situations, Information Systems and E-Business Management, 6 (2008) 295-316.

[36] J. Geldermann, V. Bertsch, M. Treitz, S. French, K.N. Papamichail, R.P. Hämäläinen, Multicriteria decision support and evaluation of strategies for nuclear remediation management, Omega, 37 (2009) 238-251.

[37] M. Ortuño, G. Tirado, B. Vitoriano, A lexicographical goal programming based decision support system for logistics of Humanitarian Aid, Top, 19 (2011) 464-479.

[38] S. Shan, L. Wang, L. Li, Y. Chen, An emergency response decision support system framework for application in e-government, Information Technology and Management, 13 (2012) 411-427. 
[39] A. Xanthopoulos, D. Koulouriotis, A Multi-agent Based Framework for Vehicle Routing in Relief Delivery Systems, Humanitarian and Relief Logistics, Springer2013, pp. 167-182.

[40] S. Kumar, T. Havey, Before and after disaster strikes: A relief supply chain decision support framework, International Journal of Production Economics, 145 (2013) 613-629.

[41] G. Kou, D. Ergu, Y. Shi, An integrated expert system for fast disaster assessment, Computers \& Operations Research, 42 (2014) 95-107.

[42] N. Slam, W. Wang, G. Xue, P. Wang, A framework with reasoning capabilities for crisis response decision-support systems, Engineering Applications of Artificial Intelligence, 46 (2015) 346-353.

[43] W. Liu, Discussion on Enterprise Emergency Management Decision Support System, Intelligence Computation and Evolutionary Computation, Springer2013, pp. 73-77.

[44] A. Gatignon, L.N. Van Wassenhove, A. Charles, The Yogyakarta earthquake: Humanitarian relief through IFRC's decentralized supply chain, International Journal of Production Economics, 126 (2010) 102-110.

[45] A. Neely, M. Gregory, K. Platts, Performance measurement system design: a literature review and research agenda, International Journal of Operations \& Production Management, 25 (2005) 12281263.

[46] B.M. Beamon, B. Balcik, Performance measurement in humanitarian relief chains, International Journal of Public Sector Management, 21 (2008) 4-25.

[47] D.C. Novak, J.L. Sullivan, A link-focused methodology for evaluating accessibility to emergency services, Decision Support Systems, 57 (2014) 309-319.

[48] S.W. Yoon, J.D. Velasquez, B.K. Partridge, S.Y. Nof, Transportation security decision support system for emergency response: A training prototype, Decision Support Systems, 46 (2008) 139-148.

[49] A. Verma, G.M. Gaukler, Pre-positioning disaster response facilities at safe locations: An evaluation of deterministic and stochastic modeling approaches, Computers \& Operations Research, 62 (2015) 197-209.

[50] A.M. Caunhye, Y. Zhang, M. Li, X. Nie, A location-routing model for prepositioning and distributing emergency supplies, Transportation Research Part E: Logistics and Transportation Review.

[51] P. Ghandforoush, T.K. Sen, A DSS to manage platelet production supply chain for regional blood centers, Decision Support Systems, 50 (2010) 32-42.

[52] R.B. Lopes, S. Barreto, C. Ferreira, B.S. Santos, A decision-support tool for a capacitated location-routing problem, Decision Support Systems, 46 (2008) 366-375.

[53] D.J. Power, R. Sharda, Model-driven decision support systems: Concepts and research directions, Decision Support Systems, 43 (2007) 1044-1061.

[54] E. Orta, M. Ruiz, N. Hurtado, D. Gawn, Decision-making in IT service management: a simulation based approach, Decision Support Systems, 66 (2014) 36-51.

[55] D. Arnott, G. Pervan, Eight key issues for the decision support systems discipline, Decision Support Systems, 44 (2008) 657-672.

[56] M.P. Fanti, G. Iacobellis, W. Ukovich, V. Boschian, G. Georgoulas, C. Stylios, A simulation based Decision Support System for logistics management, Journal of Computational Science, 10 (2015) 86-96.

[57] N.N. Ambraseys, C.P. Melville, A history of Persian earthquakes, Cambridge University Press2005.

[58] I. Armaş, Multi-criteria vulnerability analysis to earthquake hazard of Bucharest, Romania, Natural hazards, 63 (2012) 1129-1156.

[59] K.A. Hosseini, M. Hosseini, M. Jafari, S. Hosseinioon, Recognition of Vulnerable Urban Fabrics in Earthquake Zones: A Case Study of the Tehran Metropolitan Area, JSEE Journal of Seismology and Earthquake Engineering, 10 (2009) 175-187.

[60] http://www.amar.org.ir, 2012.

\section{Appendix I. The pseudo code for the proposed HDSS}

Step 1. Initialization: (Conceptual Model Parameters) 
Step 1.1. HDSSConfigParam ( $\left.\vec{L}^{T}, \vec{H}^{o}, \vec{C}^{T}, \vec{M}^{H E}\right)$; (read configuration vectors)

Step 1.1.1. For q, j, i, e, z, n; (number of HO, LT, CT, RHE, Z, N)

Step 1.1.3. For j: $=1$ to $\mathrm{J} \operatorname{Read} R_{j}, C_{j}^{L T}, B T_{j}$

Step 1.1.4. For i: $=1$ to I $\operatorname{Read} L_{i}, C_{i}^{C T}, B T_{i}$

Step 1.1.5. For e: $=1$ to E Read $\vec{E}_{e}=\left(E_{e}^{v}, E_{e}^{c a}, E_{e}^{c o}\right)$

Step 1.1.6. For $\mathrm{z}:=1$ to $\mathrm{Z}$ Read $P_{z}, \chi_{z}$

Step 1.1.7. For $\mathrm{j}:=1$ to $\mathrm{J}$

$$
\begin{aligned}
& \text { For z: }=1 \text { to } \mathrm{Z} \operatorname{Read} \hat{L}_{j}^{z} \\
& \text { For } \mathrm{n}:=1 \text { to } \mathrm{N} \operatorname{Read} \psi_{j n}^{L T}, \xi_{j n}^{L T}
\end{aligned}
$$

Step 1.1.8. For i: $=1$ to I Read

$$
\text { For } \mathrm{n}:=1 \text { to } \mathrm{N} \operatorname{Read} \psi_{i n}^{C T}, \xi_{i n}^{C T}
$$

Step 1.1.9. For e: $=1$ to $\mathrm{E}$

$$
\begin{aligned}
& \text { For } \mathrm{i}:=1 \text { to } \mathrm{I} \\
& \text { For } \mathrm{j}:=1 \text { to } \mathrm{J} \text { read } E T_{i j}^{e} \\
& \text { For } \mathrm{q}:=1 \text { to } \mathrm{Q} \operatorname{Read} E T_{i q}^{e}
\end{aligned}
$$

Step 1.1.10. For $\mathrm{z}:=1$ to $\mathrm{Z}$

$$
\text { For } \mathrm{n}:=1 \text { to } \mathrm{N} \operatorname{Read} d_{n}^{z}
$$

Step 1.1.11. For $\mathrm{q}:=1$ to $\mathrm{Q}$

$$
\text { For } \mathrm{n}:=1 \text { to } \mathrm{N} \operatorname{Read} R_{q}^{n}, \xi_{q n}^{H O}
$$

Step 1.2. DVM/config; (forming decision variable matrix)

Step 1.2.1. For e: $=1$ to $\mathrm{E}$ set $\left[U_{e}\right]_{1 \times E}$

Step 1.2.2. For $\mathrm{j}:=1$ to $\mathrm{J}$

$$
\text { For z: }=1 \text { to } \mathrm{Z} \text { set }\left[L_{j}^{z}\right]_{Z \times J} \text { and }\left[B T_{j}^{z}\right]_{Z \times J}
$$

Step 1.2.3. For $\mathrm{i}:=1$ to $\mathrm{I}$ set $\left[B T_{i}\right]_{1 \times I}$

Step 1.2.4. For $\mathrm{z}:=1$ to $\mathrm{Z}$

$$
\text { For } \mathrm{j}:=1 \text { to } \mathrm{J}
$$

$$
\text { For n: }=1 \text { to } \mathrm{N} \text { read }\left[F_{j n}^{z}\right]_{Z \times J \times N}
$$

Step 1.3. Sim/index; (simulation indexes)

Step 1.3.1. InitTime $(\mathrm{t}) ;$ (simulation time initialization) Step 1.3.2. InitTime $\left(T^{\prime}\right)$; (real period time initialization) Step 1.3.3. iteraCoun. (a); (iteration counter)

Step 2. Parameter generation

Step 2.1. $\mathrm{RVG}(\theta) ;\left(\sum_{i} \theta_{i}=\theta\right.$ and select CT randomly, $\left.i \approx U[1, I]\right)$;

Step 2.2. RVG ( $R_{q}^{n}$ );( generate $R_{q}^{n}$ randomly according to its distribution)

Step 2.3. RVG ( $\left.E T_{i q}^{e}\right)$;( generate $E T_{i q}^{e}$ randomly according to its distribution)

Step 2.4. RVG $\left(\vec{E}_{e}\right) ;\left(\right.$ generate $E_{e}^{v}, E_{e}^{c a}, E_{e}^{c o}$ randomly according to their distribution)

Step 2.5. RVG ( $\left.E T_{i j}^{e}\right)$; (generate $E T_{i j}^{e}$ randomly according to its distribution)

Step 2.6. $\operatorname{RVG}\left(\Theta_{j}^{z}\right) ;\left(\right.$ generate $\Theta_{j}^{z}$ randomly $\Theta_{j}^{z} \approx U\left[1, \hat{L}_{j}^{z}\right]$ )

Step 2.7. RVG ( $\left.\varpi_{e}\right) ;\left(\right.$ generate $\varpi_{e}$ randomly $\varpi_{e} \approx U[1, U e]$ ) 
Step 3. Sim/disaster/Imp (simulate disaster)

Step 3.1. EC (evaluation criteria creating);

Step 3.1.1. Let RS: =0;

Step 3.1.2. Let RE: $=0$;

Step 3.1.3. Let $C^{C o}:=0$;

Step 3.1.4. Let $C^{T}:=0$;

Step 3.1.5. Let $C^{B T}:=0$;

Step 3.2. SMC (create HO/CT/R, CT/LT/R super matrixes);

Step 3.2.1. HO/CT/R:

$$
\begin{aligned}
& \text { For } \mathrm{q}:=1 \text { to } \mathrm{Q} \\
& \text { For } \mathrm{n}:=1 \text { to } \mathrm{N} \\
& \text { For } \mathrm{i}:=1 \text { to } \theta \\
& \text { Let } F_{q n i}:=0
\end{aligned}
$$

Step 3.2.1. CT/LT/R

$$
\begin{aligned}
& \text { For i: }=1 \text { to } \theta \\
& \text { For n: }=1 \text { to } \mathrm{N} \\
& \text { For z: }=1 \text { to } \mathrm{Z} \\
& \text { For j: }=1 \text { to } \Theta_{j}^{z} \\
& \text { Let } F_{i j n}^{z}:=0
\end{aligned}
$$

Step 3.3. SHM (create HO/CT/E, CT/LT/E super matrixes);

Step 3.2.1. HO/CT/E

$$
\begin{aligned}
& \text { For } \mathrm{q}:=1 \text { to } \mathrm{Q} \\
& \text { For } \mathrm{n}:=1 \text { to } \mathrm{N} \\
& \text { For } \mathrm{i}:=1 \text { to } \theta \\
& \text { For e: }=1 \text { to } \varpi_{e} \\
& \text { Let } v_{i e}^{q n}:=0
\end{aligned}
$$

Step 3.2.1. CT/LT/R

$$
\begin{aligned}
& \text { For i: }=1 \text { to } \theta \\
& \text { For n: }=1 \text { to } \mathrm{N} \\
& \text { For } \mathrm{z}:=1 \text { to } \mathrm{Z} \\
& \text { For j: }=1 \text { to } \Theta_{j}^{z} \\
& \text { For e: }=1 \text { to } \varpi_{e} \\
& \text { Let } v_{i n e}^{z j}:=0
\end{aligned}
$$

Step 3.3. Sim/Dis.Model/Run(beginning simulation);

Step 3.2.1. For $\mathrm{t}=\operatorname{InitTime}(\mathrm{t})$ to InitTime $\left(t^{\prime}\right)$

Step 3.2.1.1. iteraCoun.(a):=1

Step 3.2.1.2. Read generated data (step 2.1 to 2.7 ) and formed super matrixes

Step 3.2.1.3. Allocate $F_{q n i} ;\left(\right.$ Con. $\left.F_{q n i} \approx U\left[1, R_{q}^{n}\right]\right)$

Step 3.2.1.4. Allocate $F_{i j n}^{z} ;\left(\right.$ Con. $\left.F_{i j n}^{z} \approx U\left[1, \sum_{q} F_{q n i}\right]\right)$

Step 3.2.1.5. dedicate $v_{i e}^{q n} ;\left(\right.$ Con. $\left.\varpi_{e} \times E_{e}^{c a} \times\left[T^{\prime} / 2 d_{q i} / E_{e}^{v}\right] \leq F_{q n i}\right)$

Step 3.2.1.6. Allocate $v_{i n e}^{z j} ;\left(\right.$ Con. $\left.\varpi_{e} \times E_{e}^{c a} \times\left[T^{\prime}-t / 2 d_{i j^{z}} / E_{e}^{v}\right] \leq F_{q n i}\right)$

Step 4. Simulation inference engine (Rule-base/Simulation)

Step 4.1. For iteraCoun.(a):=1: Obtain insert value RS, RE, $C^{C o}, C^{T}$ and $C^{B T}$ by equations (2)-(6) Step 4.1. Loop (iteraCoun.(a), iteraCoun. (a):=iteraCoun.(a)+1 <= MK;(Identified by DM) 
If RS.L $<=\mathrm{RS}$ and RE.L $<=\mathrm{RE}$ and $C^{C o} . \mathrm{L}<=C^{C o}$ and $C^{T} . \mathrm{L}<=C^{T}$ and $C^{B T}{ }_{. \mathrm{L}<=} C^{B T}$ then

Step 4.1.1. Store in RS.L:=RS, RE.L:=RE, $C^{C o} . \mathrm{L}:=C^{C o}, C^{T} . \mathrm{L}:=C^{T}, C^{B T}{ }_{. \mathrm{L}<=} C^{B T}$;

Step 4.1.2. Store in DB HO/CT/R.L $=H O / C T / R, C T / L T / R . L=C T / L T / R$;

Step 4.1.3. Store in DB HO/CT/E.L= HO/CT/E, CT/LT/E.L=CT/LT/E;

and run replication

else go to step 3 and reconfigure super matrixes);

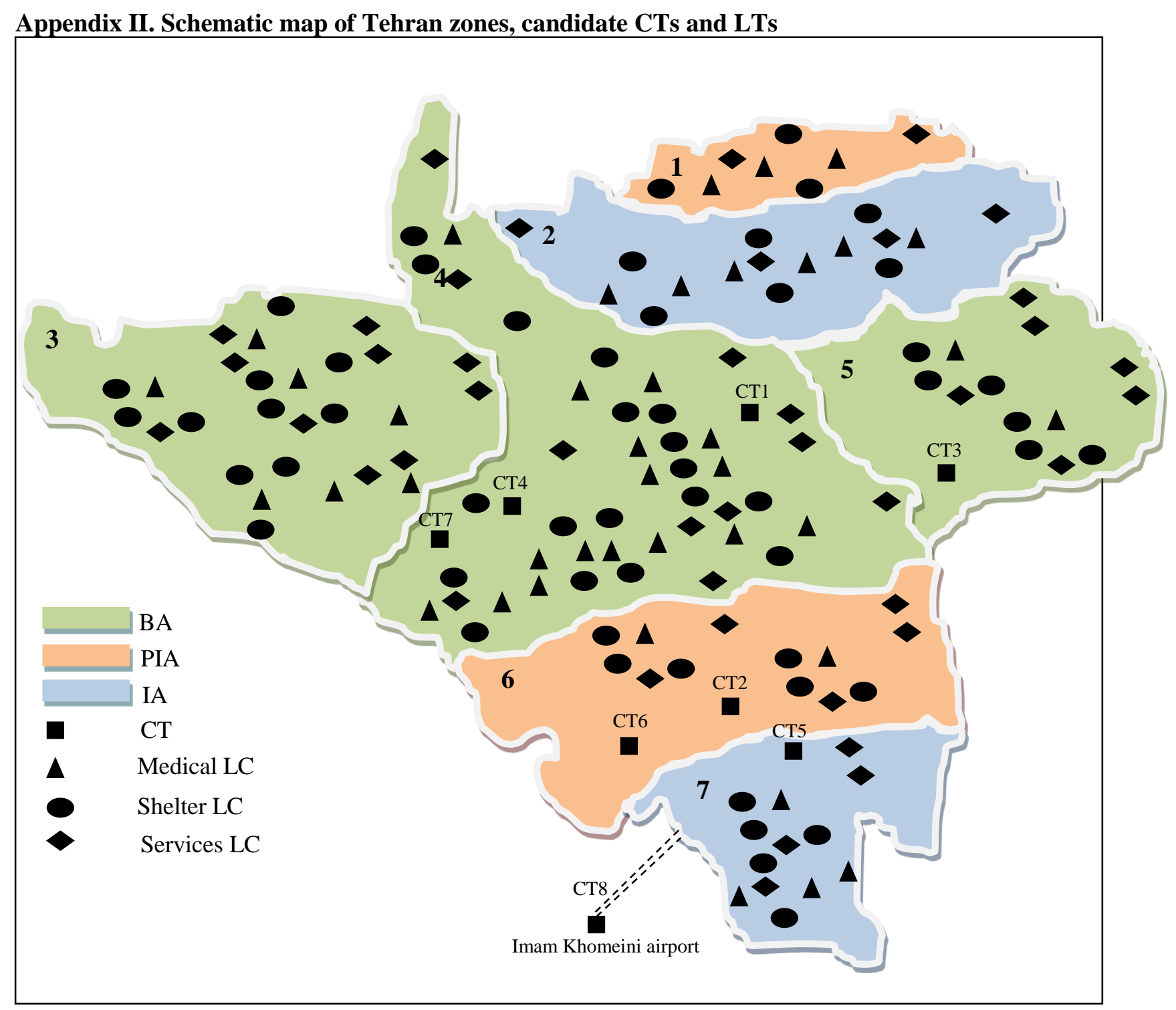

